\title{
The ASCAT Soil Moisture Product: A Review of its Specifications, Validation Results, and Emerging Applications
}

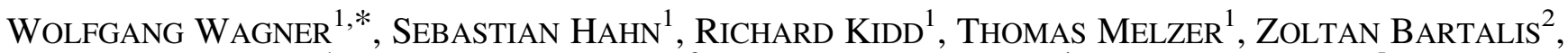

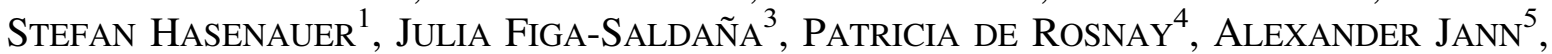 \\ STEFAN SCHNEIDER ${ }^{5}$, JÜRGEN KOMMA ${ }^{6}$, GERHARD KUBU ${ }^{7}$, KATHARINA BRUGGER ${ }^{8}$, \\ CHRISTOPH AUbrecht ${ }^{9}$, JOHANN ZÜGER ${ }^{9}$, UtE GANGKOFNER ${ }^{10}$, STEFAN KIENBERGER ${ }^{11}$, \\ LUCA BROCCA $^{12}$, YONG WANG ${ }^{5}$, GÜNTER BLÖSCHL ${ }^{6}$, JOSEF EITZINGER ${ }^{7}$, KLAUS STEINNOCHER ${ }^{9}$, \\ PETER ZEIL ${ }^{11}$ and FRANZ RUBEL ${ }^{8}$
}

${ }^{1}$ Department of Geodesy and Geoinformation, Vienna University of Technology, Vienna, Austria

${ }^{2}$ ESA, ESRIN, Frascati, Italy

${ }^{3}$ EUMETSAT, Darmstadt, Germany

${ }^{4}$ ECMWF, Reading, United Kingdom

${ }^{5}$ ZAMG, Vienna, Austria

${ }^{6}$ Institute of Hydraulic and Water Resources Engineering, Vienna University of Technology, Vienna, Austria

${ }^{7}$ Institute of Meteorology, University of Natural Resources and Applied Life Sciences, Vienna, Austria

${ }^{8}$ Institute for Veterinary Public Health, University of Veterinary Medicine, Vienna, Austria

${ }^{9}$ AIT Austrian Institute of Technology GmbH, Vienna, Austria

${ }^{10}$ GeoVille, Innsbruck, Austria

${ }^{11}$ Centre for Geoinformatics, University of Salzburg, Salzburg, Austria

${ }^{12}$ Research Institute for Geo-Hydrological Protection, National Research Council, Perugia, Italy

(Manuscript received May 5, 2012; in revised form November 21, 2012; accepted February, 2013)

\begin{abstract}
Many physical, chemical and biological processes taking place at the land surface are strongly influenced by the amount of water stored within the upper soil layers. Therefore, many scientific disciplines require soil moisture observations for developing, evaluating and improving their models. One of these disciplines is meteorology where soil moisture is important due to its control on the exchange of heat and water between the soil and the lower atmosphere. Soil moisture observations may thus help to improve the forecasts of air temperature, air humidity and precipitation. However, until recently, soil moisture observations had only been available over a limited number of regional soil moisture networks. This has hampered scientific progress as regards the characterisation of land surface processes not just in meteorology but many other scientific disciplines as well. Fortunately, in recent years, satellite soil moisture data have increasingly become available. One of the freely available global soil moisture data sets is derived from the backscatter measurements acquired by the Advanced Scatterometer (ASCAT) that is a C-band active microwave remote sensing instrument flown on board of the Meteorological Operational (METOP) satellite series. ASCAT was designed to observe wind speed and direction over the oceans and was initially not foreseen for monitoring soil moisture over land. Yet, as argued in this review paper, the characteristics of the ASCAT instrument, most importantly its wavelength $(5.7 \mathrm{~cm})$, its high radiometric accuracy, and its multiple-viewing capabilities make it an attractive sensor for measuring soil moisture. Moreover, given the operational status of ASCAT, and its promising long-term prospects, many geoscientific applications might benefit from using ASCAT soil moisture data. Nonetheless, the ASCAT soil moisture product is relatively complex, requiring a good understanding of its properties before it can be successfully used in applications. To provide a comprehensive overview of the major characteristics and caveats of the ASCAT soil moisture product, this paper describes the ASCAT instrument and the soil moisture processor and near-real-time distribution service implemented by the European Organisation for the Exploitation of Meteorological Satellites (EUMETSAT). A review of the most recent validation studies shows that the quality of ASCAT soil moisture product is - with the exception of arid environments -comparable to, and over some regions (e.g. Europe) even better than currently available soil moisture data derived from passive microwave sensors. Further, a review of applications studies shows that the use of the ASCAT soil moisture product is particularly advanced in the fields of numerical weather prediction and hydrologic modelling. But also in other application areas such as yield monitoring, epidemiologic modelling, or societal risks assessment some first progress can be noted. Considering the generally positive evaluation results, it is expected that the ASCAT soil moisture product will increasingly be used by a growing number of rather diverse land applications.
\end{abstract}

Keywords: Soil moisture, earth observation, scatterometer, hydrometeorological applications, accuracy assessment.

${ }^{*}$ Corresponding author: Wolfgang Wagner, Department of Geodesy and Geoinformation, Vienna University of Technology, Vienna, Austria, e-mail: wolfgang.wagner@geo.tuwien.ac.at 


\section{Introduction}

The Advanced Scatterometer (ASCAT) is an active microwave remote sensing instrument that was designed for monitoring of winds over the oceans in support to operational applications such as numerical weather prediction (NWP), tropical cyclone analysis, and ocean waves forecasting (ISAKSEN and STOFFELEN, 2000; FigA-SALDAÑA et al., 2002; LIU, 2002). Over land, no operational services were initially foreseen. However, research carried out with its predecessor instrument, the ERS-1/2 scatterometer (ESCAT), provided increasing evidence that ASCAT might also be used for monitoring of soil moisture (PULLIAINEN et al., 1998; WAGNER et al., 1999c; WEN uND SU, 2003; WAGNER et al., 2007a) even though it was not clear at that time whether soil moisture products derived from these instruments are able to meet the accuracy requirements of potential applications. The main concern was, and to some extent still is, that ESCAT and ASCAT are operated at a wavelength of $5.7 \mathrm{~cm}$ (C-Band) which has often been stated to be sub-optimal for the task of soil moisture retrieval due to a reduced sensitivity to soil moisture in the presence of vegetation compared to longer wavelengths such as L-Band (KERR, 2007). It has however been overlooked that ESCAT, and even more so ASCAT, are well-calibrated instruments with a high radiometric accuracy. In other words, while they offer a somewhat reduced sensitivity to soil moisture compared to L-Band instruments, their signal-to-noise ratio may still suffice to achieve an acceptable retrieval accuracy. And indeed, many of the initial ESCAT validation studies carried out by independent research teams unexpectedly found quite encouraging results (PELLARIN et al., 2006; BROCCA et al., 2009; RÜDIGER et al., 2009).

The first user community to take note of the opportunities offered by ESCAT and ASCAT was the NWP community. There are probably two reasons for this: Firstly, the importance of soil moisture for modelling land-atmosphere interactions had increasingly been recognised since the 1990s (ZHENG and ELTAHIR, 1998; KOSTER et al., 2004), prompting much research in the NWP community to improve the representation of soil moisture processes over the last decade (JEREZ et al., 2010; BARTHLOTT et al., 2011). Secondly, the spatial resolution of ESCAT and ASCAT, which is in the order of tens of kilometres $(25-50 \mathrm{~km})$, is commensurate with the requirements of NWP models, while e.g. hydrological models run on much finer spatial grids. The interest of several European NWP centres in a potential ASCAT soil moisture product led to the decision of the European Organisation for the Exploitation of Meteorological Satellites (EUMETSAT) to develop an operational global ASCAT soil moisture processing and dissemination service (BARTALIS et al., 2007; WAGNER et al., 2010). EUMETSAT implemented this service in cooperation with the Vienna University of Technology (TU Wien) and put it into operations in 2008, roughly two years after the launch of METOP-A, the first satellite to carry ASCAT. To meet the requirements of the NWP community, this service is being operated in near-real-time, i.e. the ASCAT soil moisture data are continuously being processed and distributed worldwide within 135 minutes after data acquisition. This allows the NWP centres to assimilate the ASCAT soil moisture data in their operational forecasts.

Up until now the work of the NWP centres with the ASCAT soil moisture product has concentrated on validation activities, quality assessments and scientific studies. But thanks to quite positive outcomes from several data assimilation experiments some NWP centres have already started using the ASCAT soil moisture product in an operational fashion (DHARSSI et al., 2011; DE ROSNAY et al., in press a). This shows that even though much more scientific work is still required to characterise the spatio-temporal accuracy of the retrievals, the ASCAT soil moisture product starts having a positive impact in applications. Yet, being relatively new and the first-of-its-kind, the ASCAT soil moisture service is not yet widely known to a broader research community. Given the central and unifying role of soil moisture in understanding atmospheric, hydrologic, biologic, and geomorphic processes and their interactions (LEGATES et al., 2011) it has however also a significant potential in many other applications. This review paper was thus written with a view on new potential applications, discussing the strengths, limitations, and potential applications of the ASCAT soil moisture product from a user's perspective.

\section{Mission specifications}

The ASCAT soil moisture service owes several of its attractive features to the long and successful heritage of space borne ocean wind vector monitoring programmes. In particular Europe can look back to a series of successful scatterometer missions, starting with the ERS satellite programme operated by the European Space Agency (ESA), and continuing to the on-going Meteorological Operational (METOP) satellite programme operated by EUMETSAT. The high continuity provided by these European satellite programmes (Section 2.1), in combination with the strong heritage in the sensor design from one instrument generation to the next (Section 2.2), is the basis for the continuity, reliability and promising longterm prospects of the ASCAT soil moisture service.

\subsection{Satellite programmes}

The first European scatterometer (ESCAT) was the one flown on board of the two European Remote Sensing Satellites ERS-1 and ERS-2. Together, these two satellites provided scatterometer measurements for a period of 20 years (1991-2011). ASCAT itself is being flown on a series of three polar orbiting Meteorological 
Operational (METOP) satellites, whereas the first satellite (METOP-A) was launched in October 2006 and the second (METOP-B) in September 2012. METOP-B will be flown in parallel to METOP-A in a dual satellite constellation to improve the spatio-temporal coverage of their sensors. Together with METOP-C, which is scheduled for launch in 2018, the three satellites can be expected to provide an uninterrupted stream of ASCAT backscatter observations well into the 2020s. Even for the successor instrument of ASCAT, which will be flown on board of one of the Second Generation (SG) satellites of the EUMETSAT Polar System, plans are already well advanced (LIN et al., 2012).

Similar to the two ERS satellites, METOP flies in a near-polar sun-synchronous orbit at an altitude of about $817 \mathrm{~km}$ with a repeat cycle of 29 days. In this orbit the METOP circles the earth within about 100 min, which means that the satellite completes 14 orbits per day. The equator crossing times are at 9:30 for the descending pass and 21:30 for the ascending pass, meaning that for all equatorial and mid-latitude regions ASCAT data acquisitions take place at around 9:30 respectively 21:30 local time ( \pm 1 hour). Considering the two $550 \mathrm{~km}$ wide swaths of ASCAT as described in the next section, the daily global coverage with one METOP satellite is about $82 \%$. As one can see in Fig. 1a, which shows the daily global coverage achieved by one satellite (e.g. METOP-A), the gaps in coverage are largest near the equator, while at higher latitudes full daily coverage is achieved over the two poles $\left(>65^{\circ}\right)$ and in the latitudinal belt between about $35^{\circ}$ and $55^{\circ}$. In the latitudinal belt between $55^{\circ}$ to $65^{\circ}$ there are some gaps in the daily coverage maps, but nevertheless, on average, the number of acquisitions per day is higher than one for all regions north of $40^{\circ}$. With two satellites in orbit, the gaps between $55^{\circ}$ to $65^{\circ}$ disappear, but near the equator they are still present (Fig. 1b).

A consequence of the irregular spatial coverage achieved by either the one or two satellite constellation is that also the temporal coverage is highly irregular: Sometimes two (or near the poles even more) acquisitions are taken on a single day over a selected region of interest, but on other days no data are being acquired at all. This is an important constraint in using the ASCAT soil moisture data, because applications need to be developed in such a way as to cope with the highly irregular coverage, or to settle for using interpolated (and thus more uncertain) measurements.

\subsection{Instrument}

ASCAT is a fixed fan-beam scatterometer which uses six side-ways looking antennas to illuminate two $550 \mathrm{~km}$ wide swaths to each side of the satellite track (Fig. 2). It is operated at a frequency of $5.3 \mathrm{GHz}$ (C-band) in $\mathrm{VV}$ polarisation, i.e. it both transmits and receives electromagnetic waves in vertical polarisation only (ver- tical polarisation means that the electric field vector, which defines the polarisation of the electromagnetic wave, has a vertical component relative to the earth's surface). After reception, the backscatter echoes are amplified and further processed for echo power detection. The echo power measurements are then used as input into the radar equation to calculate the so-called backscattering coefficient $\sigma^{0}$, given in units of $\mathrm{m}^{2} \mathrm{~m}^{-2}$ or, more commonly, in decibels (dB). Simply put, $\sigma^{0}$ is a measure of the electromagnetic energy intercepted and reradiated at the same wavelengths by an areal unit of the Earth's land surface. The nominal spatial resolution of the ASCAT backscatter measurements is $50 \mathrm{~km}$, but a higher resolution $\sigma^{0}$ product with about $25 \mathrm{~km}$ is also available (the resolution of the higher resolution product varies somewhat across the swath from $25 \mathrm{~km}$ to $34 \mathrm{~km}$ ). Complying with the Nyquist-Shannon sampling theorem, the grid spacing of the $50 \mathrm{~km}$ product is $25 \mathrm{~km}$, and $12.5 \mathrm{~km}$ for the $25 \mathrm{~km}$ product.

The technical specifications of ASCAT make it a suitable sensor for soil moisture retrieval for several reasons. First of all, its operation frequencies of $5.3 \mathrm{GHz}$ is within the range of microwave frequencies $(<10 \mathrm{GHz})$ where the addition of liquid water to soil strongly increases the soil dielectric constant (approximately tenfold from dry to wet soils). Therefore, when the soil moisture content increases, so does the dielectric constant at the air-soil boundary and thus backscatter. This strong dependence of the backscattering intensity on the soil moisture content implies that ASCAT $\sigma^{0}$ measurements provide a relatively direct measure of the soil moisture content over bare soils. In the presence of vegetation, the response of $\sigma^{0}$ to changes in the soil moisture content is dampened, making it important to correctly model the effect of vegetation on the overall backscatter. Of course, also surface roughness has an important effect on the $\sigma^{0}$ measurements and needs to be corrected for (Section 3.1). Other favourable technical specifications of ASCAT are:

- ASCAT backscatter measurements are well calibrated and very stable over time (WILSON et al., 2010). According to ANDERSON et al. (2012) the worst-case calibration error is $0.15-0.25 \mathrm{~dB}$ and annual changes are in the order of $0.02 \mathrm{~dB}$. This means that ASCAT is very well suited for tracking changes in soil moisture.

- With its three antennas for each swath, ASCAT takes for each pixel three independent and quasi instantaneous $\sigma^{0}$ measurements at three different azimuth angles and two different incidence angles. Particularly the last feature is important because the incidence angle behaviour of $\sigma^{0}$ is an important indicator for the vegetation density, and can hence be exploited for correcting vegetation effects in the soil moisture retrieval.

- Its spatio-temporal sampling properties allow capturing the large-scale soil moisture patterns driven by atmospheric processes (precipitation, evapotranspiration) quite well (VINNIKOV et al., 1999). 
(a)

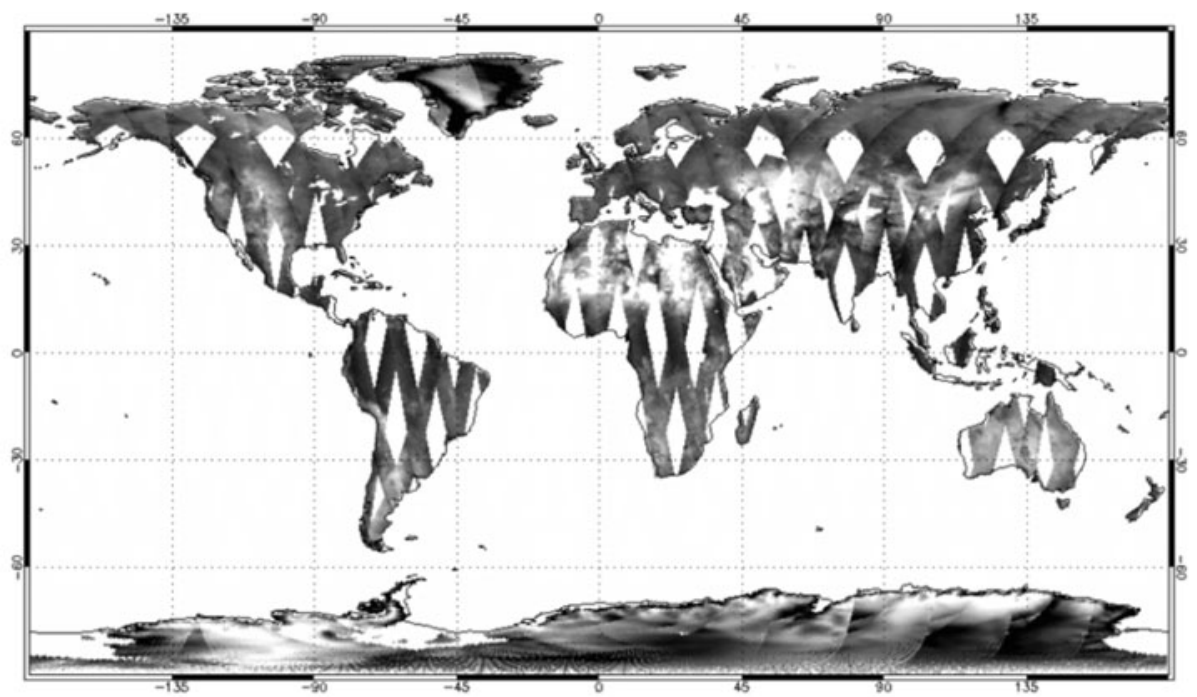

(b)

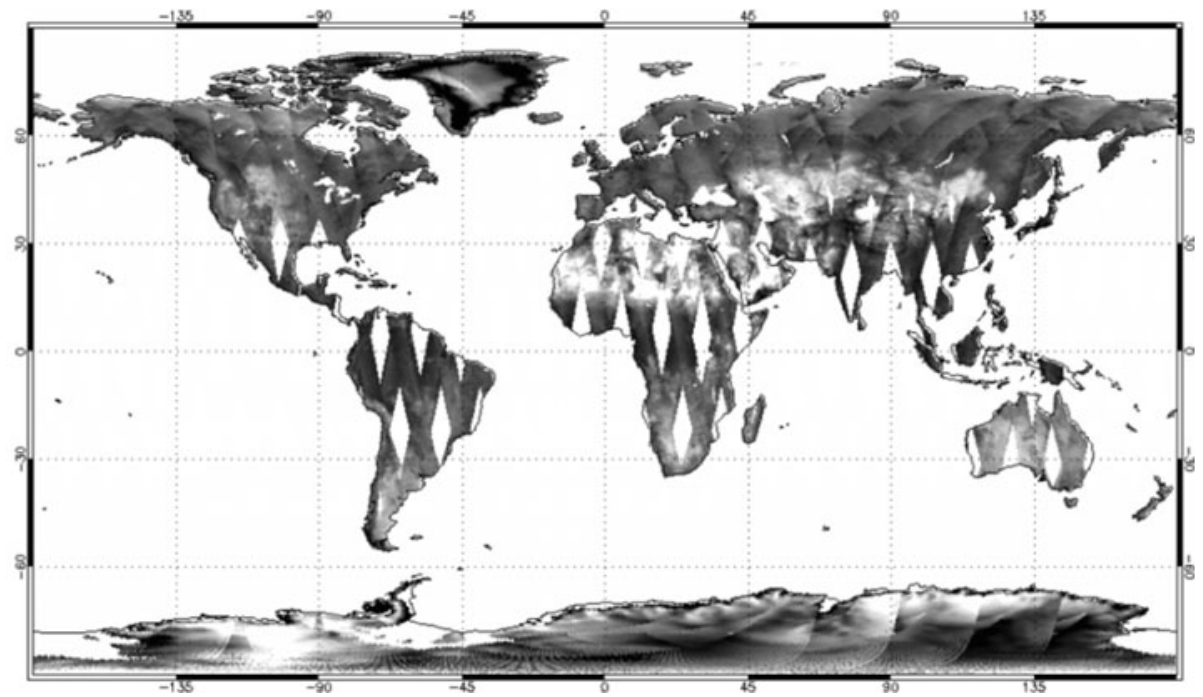

Figure 1: Daily global coverage achieved by the ASCAT instrument over land with only METOP-A in orbit (a) and with METOP-A and METOP-B in orbit (b).

\section{Product specifications}

\subsection{Physical basis}

The physical basis for the capability of ASCAT to measure soil moisture is the strong dependence of C-band backscatter on the soil moisture content in the top soil layer (usually held to be $1-2 \mathrm{~cm}$ thin). But besides soil moisture, also surface roughness has a significant effect. There are several semi-empirical and theoretical models for describing backscatter from a rough soil surface, but unfortunately, the correct characterisation of the roughness of natural surfaces still poses significant challenges (VERHOEST et al., 2008). Therefore, for the ASCAT soil moisture retrieval a change detection approach has been adopted which circumvents the problems of surface roughness parameterisation by just interpreting changes in $\sigma^{0}$ over time.
In addition to surface roughness, also vegetation has a significant effect on $\sigma^{0}$. As illustrated in Fig. 3 total backscatter from vegetation is composed of several contributions including surface backscatter from underlying ground (subject to attenuation in the canopy), canopy volume scattering, multiple path interactions between canopy and ground and double-bounce configurations between tree trunks and ground (so-called corner reflectors, a multiple-bounce over perpendicularly oriented surfaces returning the backscatter in its incident direction). Vegetation moisture content and geometric structure are thus key factors for the backscatter, especially since most structural elements of forests, shrubs etc. are comparable in size with typical microwave wavelengths $(1-25 \mathrm{~cm})$. Dense forests and shrubs are usually opaque to C-band radar, while sparse forest, grassland and agricultural crops are partly transparent. This has e.g. been demonstrated by experimental studies using range-resolving 


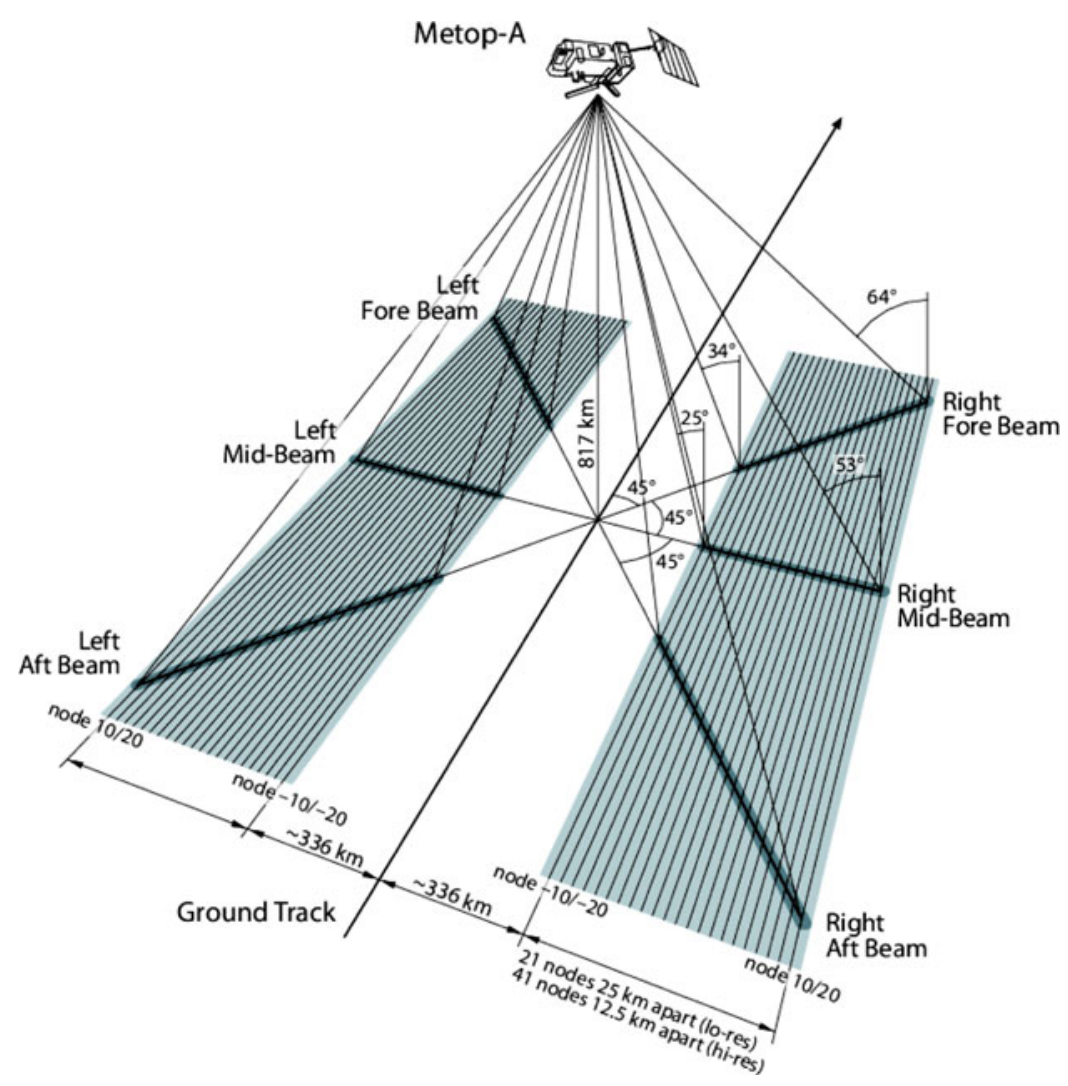

Figure 2: Imaging geometry of ASCAT.

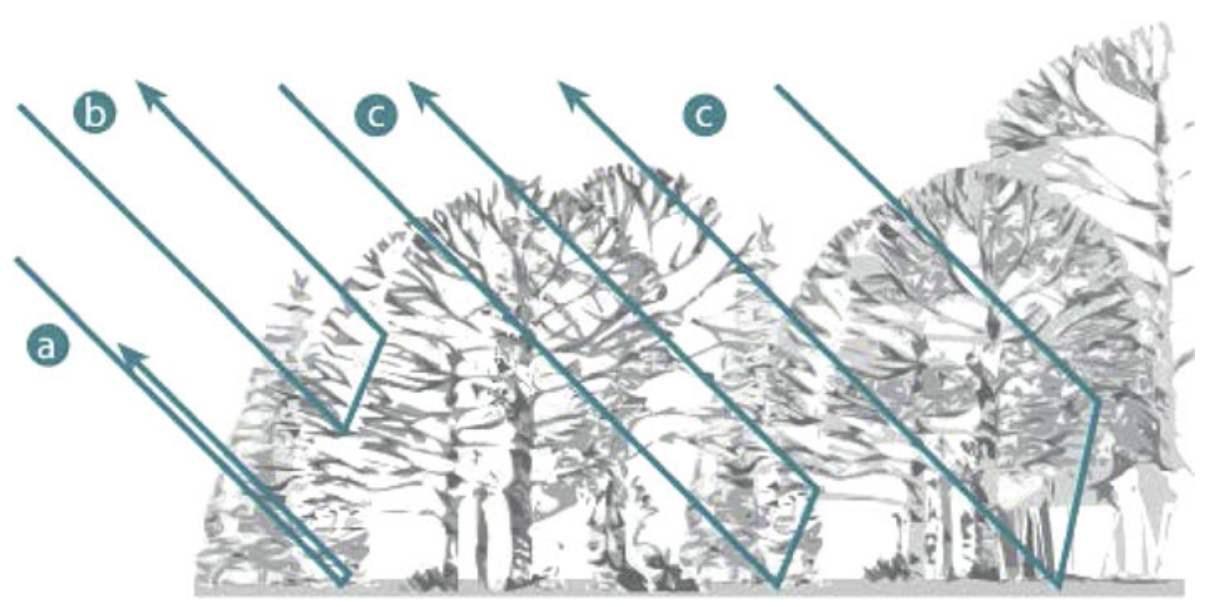

Figure 3: Illustration of the interaction of radar pulses with a vegetated surface: a) surface scattering from the ground; b) volume scattering in canopies; c) "multi-bounce" effects between vegetation and ground.

radar systems which recorded significant soil responses at C-band frequencies over these latter vegetation types even in cases when some of the theoretical backscatter models would not have predicted this (PULLIAINEN et al., 1996; BROWN et al., 2003). This was especially the case when the radar echoes were observed at lower incidence angles.

One of the most important models to describe backscatter from vegetation is the so-called Cloud Model, where vegetation is modelled as one or several layers (clouds) of water over a surface (ATTEMA and ULABY,
1978). The droplets of the clouds are randomly located and considered to be held in place by the vegetative matter. Because of the complexity it would add to the model, multiple scattering is usually not considered. Due to the aforementioned corner reflection mechanisms and possible resonant scattering, even the more complex versions of the Cloud Model remain usually just coarse approximations of the observed phenomena. Most soil moisture retrievals algorithms developed for ESCAT and ASCAT make use of the Cloud Model formulation or variants thereof (MAGagi and KeRR, 1997; PULLIAINEN et al., 
1998; WOODHOUSE and HoEKMAN, 2000; WEN and SU, 2003; ZRIBI et al., 2008). Also the ASCAT soil moisture product retrieval scheme uses a model that is very similar in functionality to the Cloud Model, depicting e.g. enhanced vegetation scattering at large incidence angles and a reduced sensitivity to soil moisture during the peak of the vegetation season (WAGNER, 1998; WAGNER et al., 1999a).

\subsection{Algorithm}

The algorithm for the ASCAT soil moisture product was developed by the Vienna University of Technology (TU Wien) and is from its conception a change detection method. The first realisation of the concept was based on ESCAT (WAGNER et al., 1999c; SCIPAL et al., 2002; WAGNER et al., 2003) and later the approach was successfully transferred to ASCAT (BARTALIS et al., 2006; BARTALIS et al., 2007; NAEIMI et al., 2009a; NAEIMI et al., 2009b). The soil moisture retrieval algorithm is implemented within a software package called WAter Retrieval Package (WARP). WARP can be used for estimating the model parameters and for deriving long-term soil moisture time series. For the operational near-realtime (NRT) processing scheme implemented at EUMETSAT a dedicated software package called WARP-NRT was developed. It uses the model parameters derived off-line with WARP. The advantages of this approach are that the processing at EUMETSAT is robust and very fast (less than a minute for each ASCAT orbit). A disadvantage is that changes in the calibration of $\sigma^{0}-$ if not characterised precisely - propagate into the NRT soil moisture product. This was still a significant problem during the initial operations of the ASCAT soil moisture service (HAHN et al., 2012), but has subsequently been improved by introducing more advanced calibration and updating schemes.

The TU Wien change detection algorithm is from a mathematical point of view less complex than semiempirical modelling approaches build upon the Cloud Model. It can be inverted analytically and therefore soil moisture can be estimated directly from the scatterometer measurements without the need for iterative adjustment processes. Because of this it is also quite straight forward to perform an error propagation to estimate the retrieval error for each land surface pixel (NAEIMI et al., 2009b). A disadvantage of the change detection model is that it is a lumped representation of the measurement process. Therefore the different contributions to the observed total backscatter from the soil, vegetation, and soil-vegetationinteraction effects cannot be separated as is the case for the approaches based upon the Cloud Model. It also means that it is necessary to calibrate its model parameters using long backscatter time series to implicitly account for land cover, surface roughness, and many other effects. The basic assumptions of the TU Wien change detection model are:

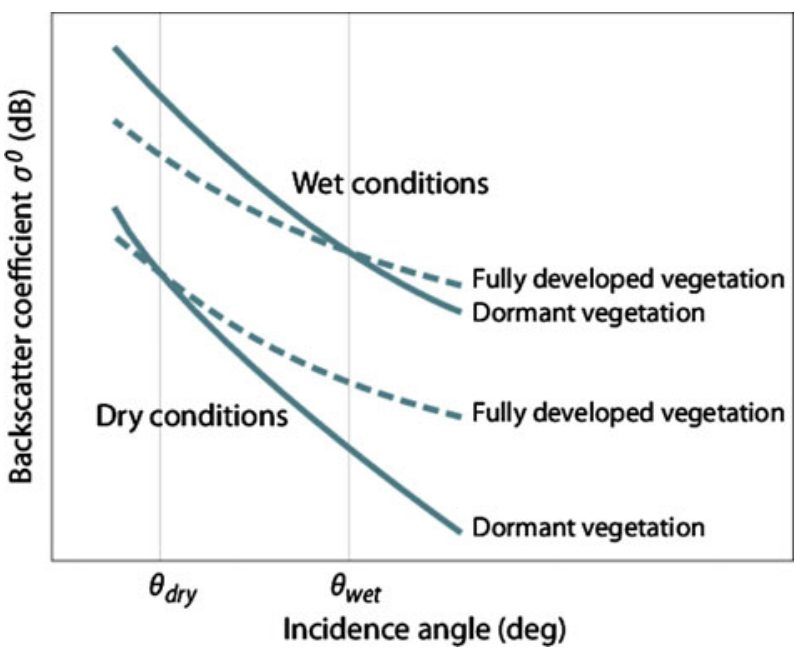

Figure 4: Illustration of the $\sigma^{0}(\theta)$ dependency on vegetation and soil moisture. Adapted from WAGNER et al. (1999a).

- The relationship between the backscattering coefficient $\sigma^{0}$ expressed in decibels (dB) and the surface soil moisture content is linear.

- At the spatial scale of the scatterometer measurements roughness and land cover are stable in time.

- The backscattering coefficient $\sigma^{0}$ depends strongly on the incidence angle $\theta$. The relationship $\sigma^{0}(\theta)$ is characteristic of the roughness conditions and land cover, but is not affected by changes in the soil moisture content.

- Vegetation phenology influences $\sigma^{0}$ on a seasonal scale. Local short-term fluctuations are suppressed at the scale of the scatterometer measurements.

While static vegetation effects are implicitly accounted for by these assumptions, there is still a seasonal vegetation component that needs to be corrected for. As illustrated by Fig. 4, backscatter may decrease or increase when vegetation grows, depending on whether the attenuation of the soil contribution is more important than the enhanced contribution from the vegetation canopy, or vice versa. It is thus possible to find a distinct incidence angle where these two physical effects cancel each other out. In other words, there is an incidence angle where the backscattering coefficient $\sigma^{0}$ is stable despite seasonal changes in above ground vegetation biomass. Given that the strength of the attenuation of the soil contribution depends on the soil moisture content there are different 'cross over' angles for dry and wet soil conditions (Fig. 4). Knowing the incidence angles $\theta_{d r y}$ and $\theta_{\text {wet }}$ where $\sigma^{0}$ does not change, it becomes possible to estimate the effects of vegetation growth at any other incidence angle given that the seasonal behaviour of $\sigma^{0}(\theta)$ can be directly derived from the multi-angular ASCAT measurements.

Processing of the ASCAT data is done in several distinct processing steps, including noise estimation and propagation, procedures to normalise the $\sigma^{0}$ measurements to account for different azimuth- and incidence 
angles, detection of frost and snow, and estimation of $\sigma^{0}$ for completely dry and wet soil conditions respectively. The surface soil moisture content $m_{s}$ is estimated in one of the last processing steps using

$$
m_{s}=\frac{\sigma^{0}-\sigma_{d r y}^{0}}{\sigma_{w e t}^{0}-\sigma_{d r y}^{0}}
$$

where $\sigma^{0}$ is the backscatter measurement to be inverted and $\sigma_{d r y}^{0}$ and $\sigma^{0}{ }_{\text {wet }}$ are the backscattering measurements representing a dry and wet earth respectively. All these $\sigma^{0}$-values are given in decibels $(\mathrm{dB})$ at a reference incidence angle of $40^{\circ}$, and vary in space and time. The surface soil moisture content $m_{s}$ is a number ranging between zero (dry) to one (wet), but normally it is given in percent. Assuming that $\sigma_{d r y}^{0}$ represents a completely dry soil surface (as might occur after some days without rain) and $\sigma^{0}{ }_{\text {wet }}$ a completely wet soil surface (as might occur during a rainfall event) $m_{s}$ is the so-called degree of saturation (HILLEL, 1982) that can be converted to the volumetric soil moisture content $\Theta$ given in $\mathrm{m}^{3} \mathrm{~m}^{-3}$ using the soil porosity $\phi$ (also given in $\mathrm{m}^{3} \mathrm{~m}^{-3}$ )

$$
\Theta=m_{s} \cdot \phi
$$

A violation of these assumptions and/or inaccurate knowledge of the soil porosity lead to a bias in the estimate of the volumetric soil moisture content. This bias can be expected to vary spatially according to climate and the quality of the available porosity data.

Overall, the results obtained in experimental validation studies for both ESCAT and ASCAT suggest that the assumptions of the TU Wien change detection model are in general quite reasonable (Section 4). Also, they have received support from new theoretical studies. For example, a recent study by CROW et al. (2010b) shows that the change detection model is better able to describe the soil moisture retrieval skill over a larger range of incidence angles than the Cloud Model in combination with the Integral Equation Model (IEM) for describing bare soil backscatter (FUNG, 1994; HSIEH et al., 1997). But of course, there are instances where one or more of these assumptions may break down and research is on-going to identify such situations. Currently the biggest problem appears to be that under extremely dry conditions, as might be found in deserts or semi-arid environments during the dry season, backscatter decreases when the soil becomes slightly wet (Section 4.2). Other assumptions, like the assumption of constant land cover, become problematic when longer time periods are considered.

\subsection{Product properties}

Both EUMETSAT and TU Wien generate and distribute a soil moisture product based on the same algorithm but with different product properties. The products can be classified according to the processor from which they are generated, their spatio-temporal representation and the production time. While the WARP NRT processor operated by EUMETSAT generates soil moisture estimates in orbit swath geometry approximately $135 \mathrm{~min}-$ utes after sensing, WARP generates soil moisture time series located on a fixed discrete global grid (KIDD, 2005). The time series are infrequently reprocessed and updated at TU Wien, taking always the most recent algorithmic updates into account. The time series product has thus a higher consistency and leads the near-real-time swath product in terms of its quality by several months or even years. Both processors (WARP and WARPNRT) rely upon the same algorithm with an important difference: Due to the processing effort in deriving model parameters and the requirement for temporally representative data time series WARP NRT uses model parameters produced by the WARP system (Fig. 5). Another difference is that EUMETSAT generates the soil moisture product at $25 \mathrm{~km}$ and $50 \mathrm{~km}$ resolutions whereas TU Wien confines the product to $25 \mathrm{~km}$. An overview of the major product properties is given in Table 1 . In the year 2012 both products became part of EUMETSAT's Satellite Application Facility on Support to Operational Hydrology and Water Management (H-SAF) which is an important milestone in guaranteeing the long-term operations of these products. Accordingly, it is foreseen to start the distribution of these products through H-SAF (http://hsaf.meteoam.it/) in the near future.

\subsection{Error propagation}

The goal of the error propagation is to provide along with each soil moisture estimate $m_{s}$ a measure of the uncertainty pertaining to it, expressed as standard deviation of its error (noise) distribution. The WARP error model propagates the initial noise estimate, the so called Estimated Standard Deviation (ESD), along the backscatter measurements through the processing chain, giving error estimates for all parameters and intermediate products that are required in order to compute the final soil moisture product (NAEIMI et al., 2009b). One exception is the estimate of the noise of the slope and curvature parameters, which is obtained not by error propagation, but by employing a Monte Carlo approach.

The ESD characterises the uncertainty due to noise sources that affect the backscatter measurements, from speckle to geo-location uncertainty and residual azimuthal effects (WAGNER et al., 1999c). It is estimated by making use of the triple-beam configuration of the ASCAT. Since all measurements are normalised by shifting them along their respective vegetation curve to a given reference angle, their uncertainty depends both on the ESD, and the uncertainty of the slope and curvature parameters (estimated with Monte Carlo) which govern the shape of the curve; this shifting occurs repeatedly at different steps in the processing chain. The final noise estimate depends primarily on the ESD and the sensitivity of the 


\section{TU Wien \\ EUMETSAT}

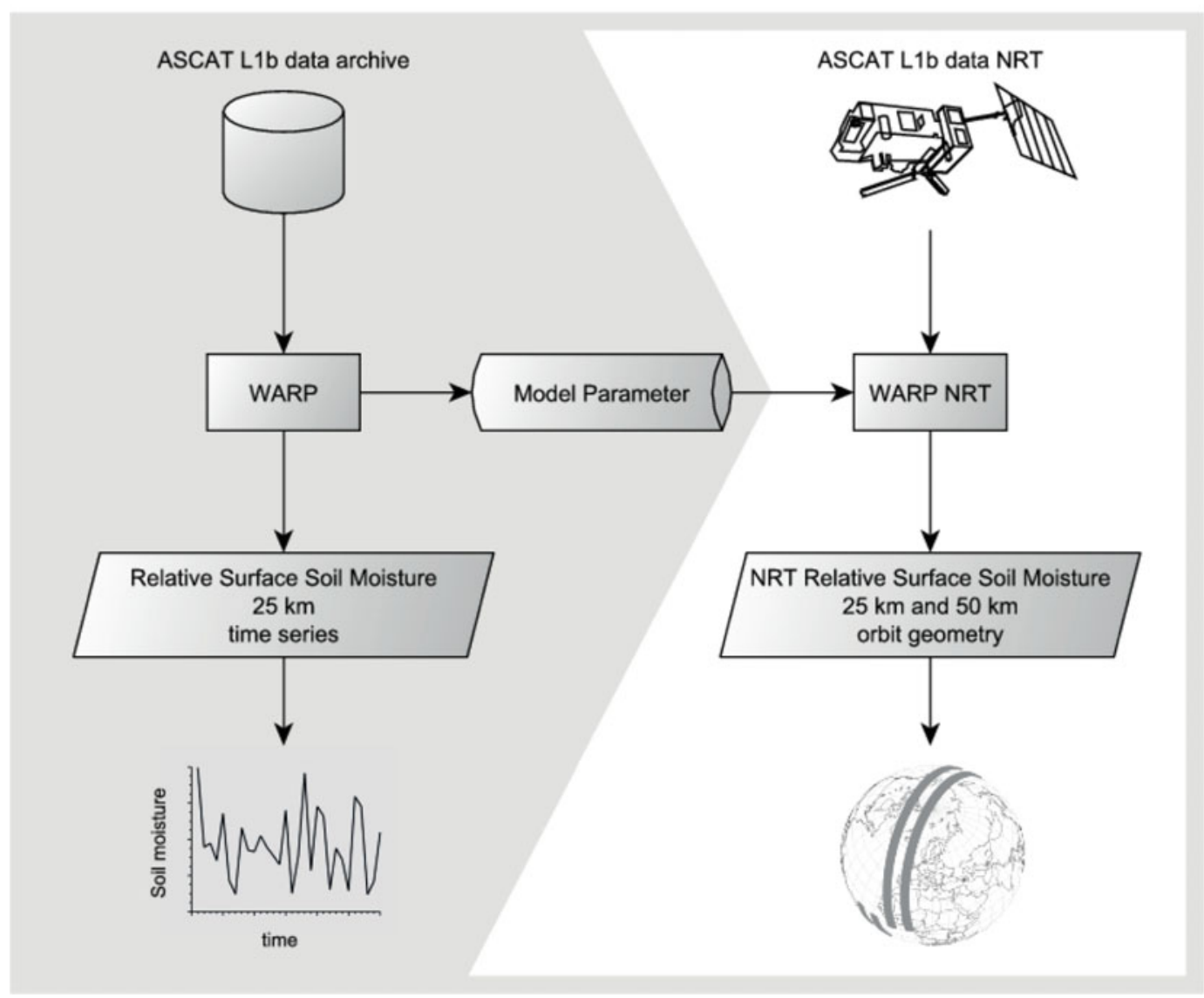

Figure 5: Overview of the data flow for WARP and WARP NRT.

Table 1: Summary of the product properties for WARP and WARP NRT as produced and distributed by TU Wien and EUMETSAT. In the future these products will also distributed by the H-SAF (http://hsaf.meteoam.it/).

\begin{tabular}{|c|c|c|c|}
\hline & WARP ASCAT Soil Moisture & \multicolumn{2}{|c|}{ WARP NRT ASCAT Soil Moisture } \\
\hline Spatial resolution & $25 \mathrm{~km}$ & $25 \mathrm{~km}$ & $50 \mathrm{~km}$ \\
\hline Spatial sampling & $12.5 \mathrm{~km}$ & $12.5 \mathrm{~km}$ & $25 \mathrm{~km}$ \\
\hline Grid & WARP 5 Grid (sinusoidal DGG) & 82 nodes per swath row & 41 nodes per swath row \\
\hline Grid reference system & Goddard Earth Model 6 (GEM 6) & \multicolumn{2}{|c|}{ World Geodetic System 1984 (WGS 84) } \\
\hline Distributor & TU Wien & \multicolumn{2}{|c|}{ EUMETSAT } \\
\hline Data structure & Time series & \multicolumn{2}{|c|}{ Orbit swath geometry } \\
\hline File format & Binary & \multicolumn{2}{|c|}{ EPS Native, EPS HDF5, BUFR } \\
\hline Temporal availability & 2007/01/01 - ongoing (infrequently updated) & \multicolumn{2}{|c|}{ 2007/06/01 - ongoing (near-realtime) } \\
\hline Dissemination & On request via FTP & \multicolumn{2}{|c|}{$\begin{array}{l}\text { EUMETCast based on standard Digital Video Broadcast } \\
\text { (DVB) technology }\end{array}$} \\
\hline Reference URL & http://www.ipf.tuwien.ac.at/radar & \multicolumn{2}{|c|}{$\begin{array}{l}\text { http://www.eumetsat.int/Home/Main/DataAccess/ } \\
\text { EUMETCast/index.htm }\end{array}$} \\
\hline Spatial coverage & \multicolumn{3}{|c|}{$60^{\circ} \mathrm{S} 180^{\circ} \mathrm{W}-80^{\circ} \mathrm{N} 180^{\circ} \mathrm{E}$} \\
\hline Soil moisture unit & \multicolumn{3}{|c|}{ relative value $(0=$ dry and $100=$ saturated $)$} \\
\hline
\end{tabular}

backscattering coefficient to soil moisture changes. The sensitivity, defined by the difference of wet and dry backscatter $\sigma_{w e t}^{0}-\sigma_{d r,}^{0}$ is a good measure of vegetation density. Over tropical forests and other densely vegetated regions, backscatter variations and hence the sensitivity are very small $(<2 \mathrm{~dB})$, thus yielding a high soil moisture retrieval error (Fig. 6). The highest sensitivity, with values in the range from 8 to $12 \mathrm{~dB}$, can be found over grassland- and agricultural areas, giving the best soil moisture estimates. 


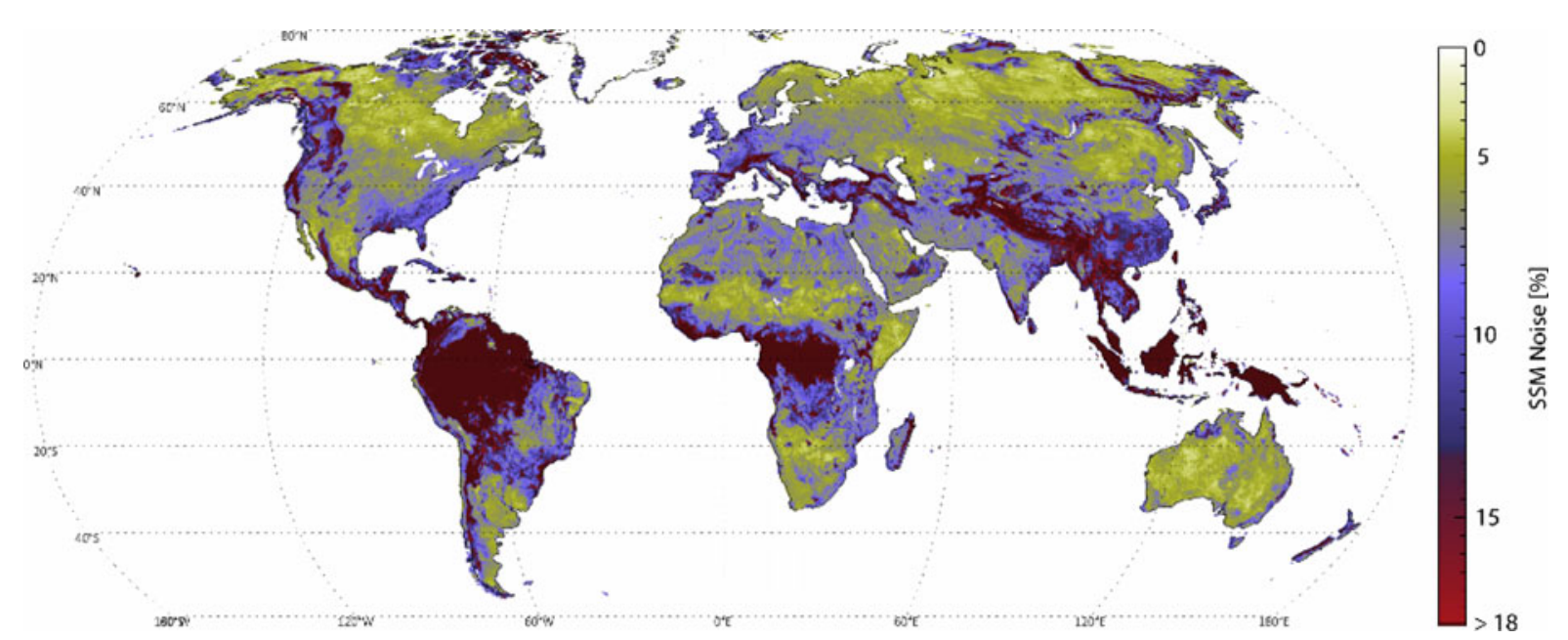

Figure 6: Spatial error field of the ASCAT soil moisture product obtained from error propagation. The figure is based upon the methods presented in NAEIMI et al. (2009b).

\subsection{Advisory flags}

In certain situations, for example when open water, snow or frozen soils dominates the satellite footprint, the retrieval of soil moisture is heavily impacted or not possible at all. The impact of these effects is not explicitly part of the TU Wien change detection model, which nonetheless estimates a soil moisture value in these situations. Therefore, aside from the astute analysis of soil moisture values themselves, the subsequent advisory flags for snow, frozen soil, surface water fraction, and topographic are also provided with EUMETSAT's NRT product. They are important for users in judging the validity of the derived soil moisture estimates. Even so, users of the ASCAT soil moisture product are advised to use the best auxiliary data available to them for improving the flagging of non-valid soil moisture retrievals. For example, if users are only interested in historic time series they may use reanalysis data to improve the flagging of snow and frozen soil. Similarly, when a user has access to dynamic maps of surface water extent they should use these data for more accurate masking of the ASCAT soil moisture data.

\subsubsection{Snow}

Backscatter from snow is often considered to consist of three components: scattering from the top snow surface, the underlying ground surface and the volume scattering from within the snow pack (ULABY et al., 1986; FUNG, 1994). The exact scattering behaviour depends on several physical parameters of the snow layer, including the liquid water content, the roughness of the air-snow interface, the layering of the snow pack, and the grain size and shape. In terms of the backscattering characteristics a snow layer can be classified into dry or wet, depending on the liquid water content, which in turn has an influence on the penetration depth of the signal. Under dry conditions the scatterometer signal penetrates the snow pack to a large extent, making the ground below the snow acting as the major source for the backscatter. In contrast, snow surface scattering is the dominating scattering mechanism for wet snow, which makes the roughness of the snow surface the most important parameter determining backscatter. For example, a wet snow with a smooth surface might have a lower signal than a dry bare soil. If, however, the snow surface is very rough then the backscatter is comparable to a wet bare soil. Since snow scattering phenomena are not treated by the TU Wien model, additional information is required to determine if snow was present or not. A snow advisory flag based on a historic analysis of SSM/I snow cover data (NOLIN et al. 1998) gives the probability of the occurrence of snow for a particular day. This flag provides the possibility to exclude soil moisture estimates most likely affected by snow cover, but should be replaced by actual snow cover information if available.

\subsubsection{Frozen soil}

The soil dielectric constant strongly decreases at temperatures below $0{ }^{\circ} \mathrm{C}$ due to the inability of the soil water molecules to align themselves to the external electromagnetic field. As a result, backscatter drops and frozen soil shows comparable backscatter characteristics as dry soil at microwave frequencies (HALLIKAINEN et al., 1984). In the case of vegetation the effect of freezing is more complex, because of the different strategies of plants to avoid freezing. In order to exclude soil moisture estimates governed by frozen soil conditions, a frozen land surface flag based on a historic analysis of modelled climate data (ERA-40) (UPPALA et al., 2005) is part of the advisory flags. It gives, similar to the snow advisory flag, the probability of frozen soil conditions for each day of the year. 


\subsubsection{Surface Water Fraction}

Due to the short penetration depth $(<1-2 \mathrm{~mm})$ of C-band microwaves into water, backscatter characteristics are primarily controlled by the roughness of the water surface. In case of a smooth, calm surface, water acts like a mirror (so-called specular reflection) and almost the complete signal scatters into the forward direction. But near surface winds are able to generate waves that cause an increase of backscatter with a maximum when the radar looks into the upwind or downwind direction, and lowest when it looks normal to the wind direction. It is exactly this effect that is exploited for the retrieval of the wind direction of open water (STOFFELEN, 1998). In case of surface soil moisture retrieval the contribution of open water has a disturbing influence on the signal if the area covered by open water surface within the footprint is large. Therefore an inundation and wetland flag, derived from the Global Lakes and Wetlands Database (LEHNER and DöLL, 2004), provides information on the fraction of water covered by the surface. This is a static flag and hence does not account for dynamic wetlands and temporary inundation. If possible it should be replaced by actual observation of surface water extent as can e.g. be derived from Synthetic Aperture Radar (SAR) imagery (BARTSCH et al., 2009b; SCHUMANN et al., 2009).

\subsubsection{Topographic complexity}

In mountainous areas backscatter can show significant variations which are not necessarily coupled with soil moisture changes. The high variability of the surface topography directly influences the scattering behaviour. Calibration errors resulting from the differences between the real surface and the assumed ellipsoid can also have an impact on the backscatter. For this reason, a topographic complexity flag, derived from a global digital elevation model (GTOPO30) data is provided. The flag contains a standard deviation of the elevation normalized to the values between 0 and 100 and enables an initial understanding of the underlying local topographic conditions.

\subsection{Higher Level Products}

As discussed in the introduction, the ASCAT soil moisture product is potentially of interest in a rather diverse set of applications. As the requirements of different applications may vary significantly, there is a need to combine the original ASCAT satellite retrievals with auxiliary data to produce a range of value added soil moisture product. For example, many applications are not interested in the soil moisture content of the thin $(1-2 \mathrm{~cm})$ remotely sensed soil layer, but require estimates of the soil moisture content in the soil profile. This requirement is addressed by the Soil Water Index (SWI) product (Section 3.6.1) and by data assimilation schemes as the one of the European Centre for Medium-Range Weather Forecasts (ECMWF) discussed in Section 3.6.2. Another important requirement of many applications is to have finer resolution soil moisture data. One approach to disaggregate the $25 \mathrm{~km}$ ASCAT soil moisture data to a $1 \mathrm{~km}$ scale is presented in Section 3.6.3.

\subsubsection{Soil Water Index}

Estimating the profile soil moisture content from one single ASCAT surface soil moisture image is not possible; the deeper soil layers may either be wetter or drier than the soil surface depending on the weather conditions within the last few days to weeks. However, thanks to the capability of ASCAT to monitor the surface soil moisture conditions with a relatively short repeat interval of 1-2 days it becomes possible to estimate the profile soil moisture content by convoluting the surface time series with an exponential function (WAGNER et al., 1999b; CeBAllos et al., 2005):

$$
S W I(t)=\frac{\sum_{i} m_{s}\left(t_{i}\right) \exp -\left[\frac{t-t_{i}}{T}\right]}{\sum_{i} \exp -\left[\frac{t-t_{i}}{T}\right]} \text { for } t_{i}<t
$$

where $\operatorname{SWI}(t)$ is the Soil Water Index at time $t, m_{\mathrm{s}}\left(t_{i}\right)$ are the ASCAT surface soil moisture retrievals at times $t_{i}$, and $T$ is the so-called characteristic time length. The effect of the convolution is to smooth and retard the soil moisture time series, mimicking the diffusion process of the water into the deeper soil layers. The resulting SWI time series has an exponential autocorrelation function with a characteristic time length $T$, agreeing with theoretical expectations (DELWORTH and MANABE, 1988) and empirical observations (VINNIKOV et al., 1996). Despite its simplicity, the SWI method has been found to approximate the profile soil moisture content quite well, with $T$ depending mainly on the soil depth and to a lesser extent on soil texture (DE LANGE et al., 2008). Using the iterative model formulation introduced by ALBERGEL et al. (2008) it becomes possible to calculate the SWI at regular intervals, e.g. daily, in a quasi near-real-time fashion. Having been more often requested by users than the surface soil moisture retrievals themselves, a near-real-time SWI processing chain has been implemented within the framework of the "geoland2" project funded by the GMES (Global Monitoring for Environment and Security) programme of the European Commission and ESA. The operational dissemination of the SWI product started in fall 2012.

The mathematical formulation of the SWI bears similarities to the one of the Antecedent Precipitation Index (API) which is also often being used as an indicator of the soil moisture content (TENG et al., 1993; CROW et al., 2010a). But instead of integrating over the variations of the surface soil moisture time series in the recent past, the API integrates over the preceding precipitation history. Given the strong physical connection between precipitation and surface soil moisture, SWI and API 


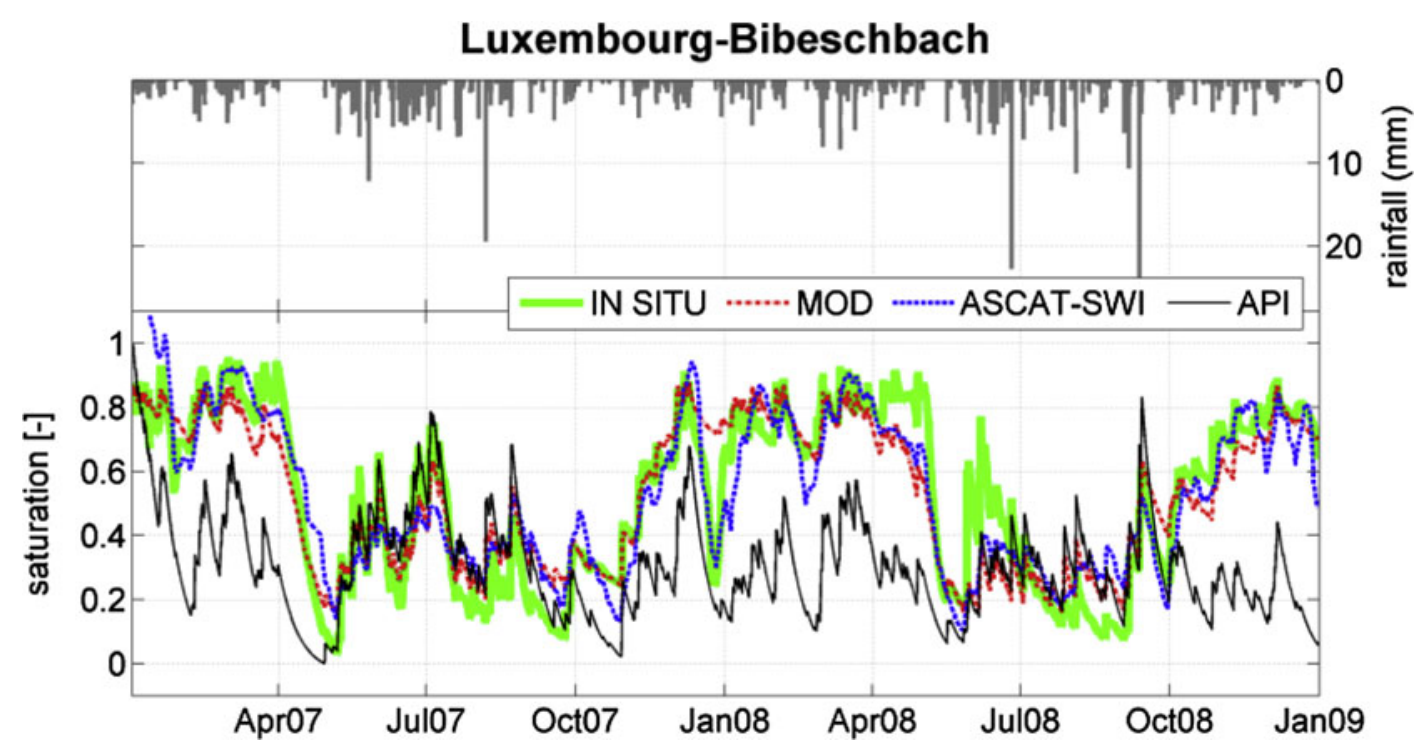

Figure 7: Comparison of ASCAT Soil Water Index (SWI) and Antecedent Precipitation Index (API) time series to precipitation (top) and in-situ (IN SITU) and modeled (MOD) soil moisture data over the Bibeschbach catchment in Luxemburg for the years 2007 and 2008.

may accordingly behave similar, particularly at short time scales. But differences may occur because the API does not describe the effects of evaporation and local runoff processes on soil moisture, which should naturally be captured by the ASCAT surface soil moisture observations. This is evident in Fig. 7 that compares SWI and API time series to in-situ and modelled soil moisture data over the Bibeschbach catchment in Luxemburg (MATGEN et al., 2012b). One can see that while short term fluctuations in all four data sets compare quite well, the seasonal soil moisture cycle is captured by the SWI but not by the API.

\subsubsection{Profile soil moisture through data assimilation}

Another approach to estimate root zone soil moisture from near surface soil moisture relies on satellite data assimilation in Land Surface Models. Several methods have been investigated in the past few years to assimilate ASCAT and passive microwave near surface soil moisture products using nudging schemes (SCIPAL et al., 2008a; DHARSSI et al., 2011), Extended Kalman Filters (MAHFOUF, 2010; DrAPER et al., 2011; De ROSNAY et al., in press a, b) or Ensemble Kalman Filters (REICHLE et al., 2007; DRAPER et al., 2012). For all these approaches, the Land Surface Model used in the data assimilation scheme describes the physical processes that control land-atmosphere interactions, including vertical transfer of soil moisture between the surface and root zone reservoirs.

In the context of EUMETSAT's H-SAF, an ASCAT root zone soil moisture profile product has been developed based on ASCAT surface soil moisture data assimilation in the ECMWF Extended Kalman Filter Land
Surface Data Assimilation System (DE ROSNAY et al., in press b). The retrieved ASCAT root zone soil moisture is an optimal combination between the modelled first guess, the screen-level temperature and humidity analyses, and the ASCAT-derived surface soil moisture which is propagated forward in time through the root zone profile. The ASCAT root zone soil moisture profile product is available for four soil layers from surface down to 3 meters, with a global daily coverage. It has been extensively evaluated against ground soil moisture measurements and showed to yield better estimates of soil moisture conditions when compared to model or satellite estimates alone (ALBERGEL et al., 2010; ALBERGEL et al., 2012). The ASCAT root zone soil moisture profile retrieval algorithm is now pre-operational at ECMWF, as part of the H-SAF project.

\subsection{3 $1 \mathrm{~km}$ disaggregated soil moisture}

To disaggregate coarse scale microwave measurements they are usually combined with finer resolution satellite data acquired either by synthetic aperture radars (DAS et al., 2011) or visible/infrared imagers (PILES et al., 2011). Within the framework of the H-SAF an approach to disaggregate the $25 \mathrm{~km}$ ASCAT surface soil moisture data to $1 \mathrm{~km}$ using Advanced Synthetic Aperture Radar (ASAR) data acquired by the ENVISAT satellite has been developed. The method exploits the fact that the temporal dynamics of soil moisture field is often very similar across a wide range of scales; a phenomenon usually referred to as "temporal stability" (VACHAUD et al., 1985; CosH et al., 2004; BROCCA et al., 2012b). This means that the relationship between local scale and regional scale measurements may be approximated by a linear model. In other words, when the regression parameters of 
the linear model are known, soil moisture at $1 \mathrm{~km}$ scale can be estimated from the $25 \mathrm{~km}$ ASCAT soil moisture data using

$$
m_{s}^{1 k m}(t, x, y)=c_{A S A R}(x, y)+d_{A S A R}(x, y) m_{s}^{25 k m}(t)
$$

where $m_{s}{ }^{l} \mathrm{~km}$ is the estimated surface soil moisture content over the $1 \mathrm{~km}$ area centred at the coordinates $(x, y)$ and $m_{s}{ }^{25} \mathrm{~km}$ is the ASCAT soil moisture retrieval at time $t$. The coefficients $c_{A S A R}$ and $d_{A S A R}$ are the two scaling parameters which are derived from long ASAR backscatter time series using the methods described in WAGNER et al. (2008). Some preliminary validation studies suggest that the disaggregated product compares equally well to in-situ measurements than the $25 \mathrm{~km}$ ASCAT product (ALBERGEL et al., 2010) but, overall, the added value of this product is not yet very clear given that the downscaling parameters $c_{A S A R}$ and $d_{A S A R}$ are static, i.e. all information about the temporal behaviour still comes from the original $25 \mathrm{~km}$ ASCAT soil moisture product (MATGEN et al., 2012b). Nevertheless, the product facilitates data handling and interpretation of the soil moisture information at much finer scales (through its advisory flags), making it thus a valuable product from a practical point of view.

\section{Validation}

Given that the ASCAT soil moisture product had initially not been planned as part of the METOP operations, there have been no dedicated calibration and validation $(\mathrm{Cal} \&$ Val) activities as usually being performed after the launch of new satellite missions. Even so, ASCAT has profited significantly from $\mathrm{Cal} \&$ Val activities performed within the framework of other satellite missions used for global mapping of soil moisture. Most important for ASCAT, the Soil Moisture and Ocean Salinity (SMOS) mission of ESA was launched only three years later than METOP-A in November 2009. SMOS is the first spaceborne mission that was designed specifically for the purpose of soil moisture monitoring over land (KERR et al., 2010). Its launch has been an important impetus for setting up new in-situ soil moisture networks, carrying out intensive field and airborne campaigns, and pursuing novel validation and data assimilation approaches (DELWART et al., 2008). The preparations of the National Aeronautics and Space Administration (NASA) in view of the upcoming launch of the Soil Moisture Active Passive (SMAP) mission in the 2014/15 time frame (ENTEKHABI et al., 2010a) have also been very important. And finally, also the increasing availability of soil moisture data derived from multi-frequency microwave radiometers such as AMSR-E (Advanced Microwave Scanning Radiometer for EOS) or WindSat have invigorated research- and validation activities in the soil moisture domain (WAGNER et al., 2007b). Consequently, there has been rapid progress in our ability to validate global satellite soil moisture products in recent years, even though basic physical issues such as scaling and sensing depth continue to hamper the interpretation of validation results.

\subsection{Validation issues}

The validation of spaceborne soil moisture retrievals is challenging for two main reasons: Firstly, soil moisture is highly variable in space and time (WESTERN et al., 2002), making it very difficult to match the intermittent and spatially irregular satellite measurements with independent reference data. Secondly, there is no reference data set which represents exactly the same physical quantity as measured by the satellite (CROW et al., 2012). When comparing satellite- with in-situ soil moisture measurements the main problems are the vastly different spatial support ( $25 \mathrm{~km}$ versus point-like measurements) and the different soil layers (a 1-2 cm thin remotely sensed topsoil layer exposed to atmospheric processes versus a probe installed at a "protected" depth of minimum $5 \mathrm{~cm})$. Because models can be tuned to match the scale and sensing depth of the satellite data, these two issues are less of a problem when comparing satellite- and modelled soil moisture data. In fact, satellite and model data often compare better with each other than each of them with the in-situ measurements (PELLARIN et al., 2006). But, of course, modelled soil moisture data are also uncertain because of model imperfection and errors of the input data (precipitation, soil properties, etc.). Therefore, correlations between satellite, in-situ and model soil moisture data are usually not very high (typical $R$ values are between 0.5 and 0.8 ), and even a complete lack of correlation does not necessarily mean that the satellite data is wrong. For example, it may also be the case that the in-situ data are not representative for a larger area or that the modelled data are not of sufficient quality. In light of these issues, it is probably more appropriate to interpret validation results in a relative context (e.g. assessing the relative performance of a number of different satellite data sets against the same in-situ and model data) rather than attributing "absolute" meaning to the results. Furthermore, it would probably be better to use the term "evaluation" rather than "validation" when comparing the satellite data to in-situ measurements. Within the framework of this paper we nevertheless stick to the term "validation" as it is the official notation used by space agencies and related international coordinating bodies such as the Committee on Earth Observation Satellites (CEOS).

One hotly disputed question in this context is how much physical meaning can or should be attributed to the absolute value of the satellite based soil moisture retrievals? One school of thought stresses the need to obtain unbiased volumetric soil moisture retrievals expressed in $\mathrm{m}^{3} \mathrm{~m}^{-3}$ (JACKSON et al., 2010). In this view, the main goal of validation activities is to determine the bias and root mean square error (RMSE) through a direct 


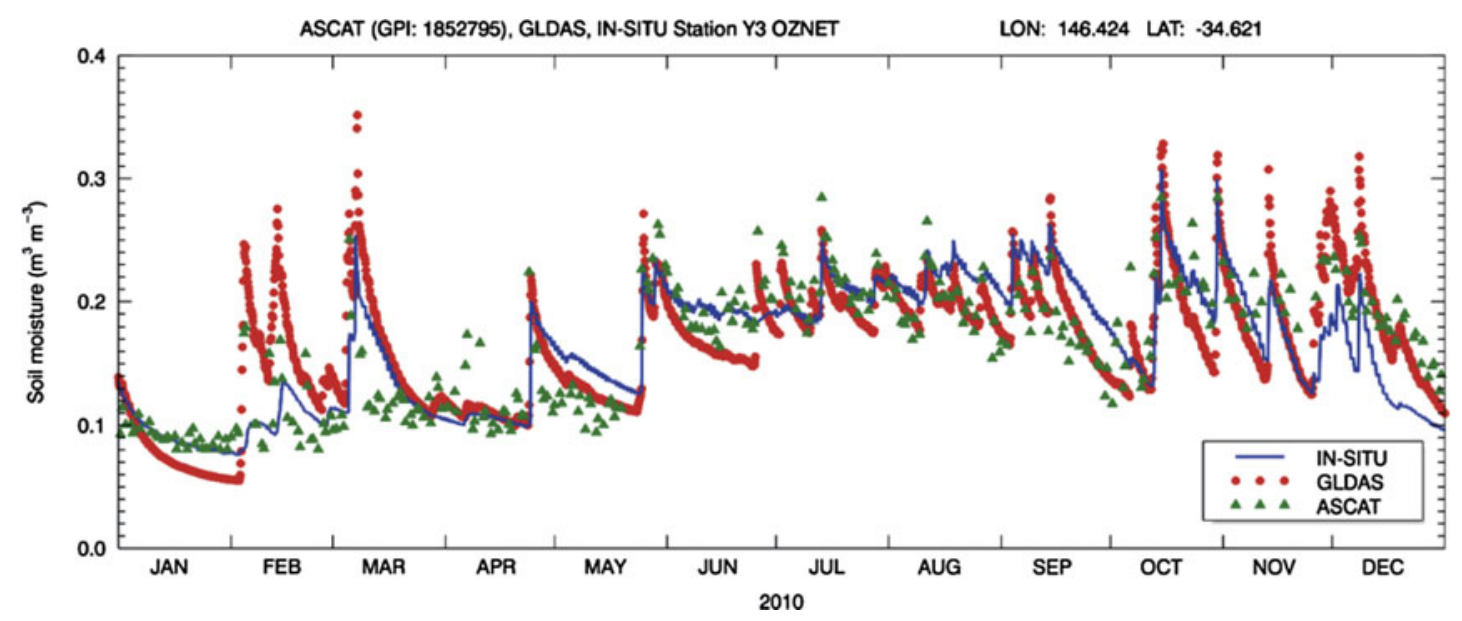

Figure 8: Comparison of ASCAT surface soil moisture time series with $5 \mathrm{~cm}$ in situ measurements acquired at one station (Y3) of the OZNET network located in south eastern Australia (RÜDIGER et al., 2007), and modeled $10 \mathrm{~cm}$ soil moisture data extracted from the Global Land Data Assimilation System (GLDAS) for the year 2010. In this example, both the ASCAT and GLDAS data were scaled to match the absolute value and dynamic range of the in situ measurements.

comparison of satellite retrievals and spatially representative in-situ measurements. Unfortunately, because soil moisture may vary strongly within meters due to variable soil properties, vegetation, and fine-scale topography, spatial soil moisture patterns are difficult to characterise using in-situ measurements and soil maps. Therefore, also the meaning of the absolute value of in-situ and modelled soil moisture data is questionable (KOSTER et al., 2009), possibly with the exception of few wellinstrumented and well-characterised "super sites". On the other hand, due to the temporal stability phenomenon mentioned before (Section 3.6.3) temporal trends in all three data types should in general agree across different spatial scales because temporal changes in soil moisture are driven by atmospheric processes from local to regional scales (ENTIN et al., 2000). This phenomenon is in fact the reason why coarse resolution satellite measurements and point scale in-situ measurements taken at one or few locations within the satellite footprint may be correlated at all. The second school of thought thus works along the principle that, as long as the satellite retrievals reproduce the time variability of the true soil moisture accurately, they can be biased in their mean and dynamic range and still be useful (ENTEKHABI et al., 2010b). In this view, the different soil moisture data are first matched so that their Cumulative Distribution Functions (CDFs) agree (DRUSCH et al., 2005; REICHLE et al., 2007). As illustrated in Fig. 8, after linear or higher-order CDF matching the ASCAT soil moisture data can be directly compared to in-situ and modelled soil moisture data (in the unit of the chosen reference). Only then the (unbiased) RMSE, correlation and other statistical measures are calculated. Practically all ASCAT validation studies have adopted this latter approach and therefore all results reported in the next section refer to bias corrected ASCAT soil moisture data.

\subsection{Validation over experimental sites}

The ASCAT soil moisture data have already been validated over several well instrumented test sites situated in different climatic regions with different land cover. The very first ASCAT soil moisture validation study was carried out by ALBERGEL et al. (2009) who compared initial near-real-time ASCAT soil moisture retrievals to in-situ measurements taken at $5 \mathrm{~cm}$ depth over 13 stations situated in south-western France for the year 2007. The average correlation value was about 0.55 for the original ASCAT values, their short term anomalies and also the derived SWI data. Overall the results were quite positive, albeit at two stations (one located in a mountainous region) no significant correlations were obtained. BROCCA et al. (2010a) validated an improved version of the ASCAT product (produced off-line by TU Wien) over a site in Central Italy using both in-situ and simulated soil moisture data. In accordance with the improved product quality the correlation and RSME improved compared to the results obtained by ALBERGEL et al. (2009). Most notably, the correlation coefficient for the SWI was higher than 0.92 and 0.8 when compared to the in-situ and model simulations respectively. The bias corrected RMSE was around $0.04 \mathrm{~m}^{3} \mathrm{~m}^{-3}$ which corresponds to the accuracy goal of both the SMOS and SMAP missions. Very comparable results were obtained by MATGEN et al. (2012b) who validated the same ASCAT product over the much more densely vegetated study site over the Bibeschbach experimental catchment in Luxemburg (cf. Fig. 7). Despite about $46 \%$ of the catchment are covered by forests, also in this case correlation values higher than 0.8 and RMSE values smaller than $0.04 \mathrm{~m}^{3} \mathrm{~m}^{-3}$ where obtained.

While most validation results over experimental sites have been very encouraging, there were of course also 
studies that reported relatively high errors and unexpected problems. For example, a lower correlation $(\mathrm{r}<$ 0.72 ) between ASCAT and in-situ measurements was found by DENTE et al. (2012) over the Maqu soil moisture monitoring network set up on the north-eastern fringe of the Tibetan Plateau. The high elevation of the network (3200-4200 m) and the long winter periods most likely had an effect on the correlation. Also, some unexplainable data spikes and differences between ascending and descending passes suggested some imperfections of the ASCAT data processing over this high-elevation area. Other validation studies carried out over arid or semi-arid environments point to a systematic retrieval error when the soil is extremely dry (WAGNER et al., 2003; WAGNER et al., 2007b; GRUHIER et al., 2010). Rather than approaching soil moisture values near zero, it has been observed that the retrieved soil moisture values may increase after several weeks without rain. The physical reasons for this phenomenon are not yet fully understood but it is hypothesised that the scatterometer signal penetrates deeper into the soil under extremely dry conditions. This is because water is not only a strong scatterer but also a strong absorbent of low frequency microwaves (SCHANDA, 1986). Therefore, the penetration depth increases quasi exponentially when the soil becomes depleted of water (WILLIAMS and GREELEY, 2001). This may cause volume scattering from deeper soil layers or scattering by subsurface discontinuities e.g. a rock surface beneath a shallow soil layer (MÄTZLER, 1998; ELSHERBINI and SARABANDI, 2010), potentially leading to enhanced backscatter and hence higher soil moisture retrievals. Research is on-going to understand, and if possible correct for this phenomenon.

The increasing availability of in-situ soil moisture data worldwide (KRAUSS et al., 2010), available e.g. through the International Soil Moisture Network (DoRIGO et al., 2011), implies that more and more validation studies use data from more than one network. One noteworthy study was the one of BROCCA et al. (2011) who compared the ASCAT soil moisture product to three AMSR-E products over 17 sites located in four countries across Europe (Italy, Spain, France and Luxemburg). Overall the performance of the ASCAT product was very good, typically being better or comparable with the best of the three AMSR-E products which was derived with the Land Parameter Retrieval Model (LPRM) (DE JEU et al., 2008; OwE et al., 2008). Another such study was the one by ALBERGEL et al. (2012) who compared the near-real-time ASCAT product of EUMETSAT with first SMOS soil retrievals over more than 200 stations located in Africa, Australia, Europe and the United States. They found average correlations of 0.53 and 0.45 for ASCAT and SMOS respectively, suggesting that ASCAT retrieval capabilities are comparable to the ones of SMOS. This was not expected given that SMOS is operated at L-band which, as discussed before, is generally be considered to be superior to C-band for the task of soil moisture retrieval (KERR, 2007). This finding finds however support through another recent study carried out by PARRENS et al. (2012) who even found that ASCAT outperformed SMOS over France, possibly related to the fact that SMOS is affected by Radio Frequency Interferences (RFI) over Europe. Much more work is required to establish the performance of ASCAT relative to SMOS and other satellite sensors such as AMSR-E, but already at this stage it can be concluded that the accuracy of the ASCAT soil moisture product is much better than expected from a sensor that was not designed for that purpose.

\subsection{Triple collocation}

The validation of the ASCAT soil moisture data over experimental sites allows a quantitative assessment of the retrieval accuracy. However, by their very nature such assessments do not provide spatially complete error fields which are important for understanding the variable product quality across different environments. Therefore direct comparisons with model simulations and other satellite data sets (DIRMEYER et al., 2004; DE JEU et al., 2008; SINCLAIR and PEGRAM, 2010) will remain an important component of any Cal \& Val activity, even though the interpretation of the results will always be hampered by the (often unknown) accuracy of the reference data set. One approach which aims to overcome some of the difficulties encountered when comparing only two data sets is the so-called triple collocation technique. Triple collocation (albeit called differently by some authors) has for long been applied for estimating the errors of different satellite products, such as evapotranspiration (ROSEMA, 1993) or ocean winds (STOFFELEN, 1998). SCIPAL et al. (2008b) were the first to apply triple collocation to the problem of estimating the retrieval error of three independent soil moisture data sets, soon being followed by other research teams (DORIGO et al., 2010; MIRALles et al., 2010; HAIN et al., 2011; LEROUX et al., 2011). The basic idea behind triple collocation is that the error structure of three independent data sets can be resolved if the errors are uncorrelated. Resolving the complete error co-variance structure just based on the different data sets themselves is unfortunately not possible, which is why ZWIEBACK et al. (2012) emphasise the necessity of expert knowledge for deciding if the assumption of uncorrelated errors is met or not. In practice this means that one has to be very careful of choosing only satellite- and modelled soil moisture data sets which were derived in a completely independent manner (different sensors, input data, algorithms, etc.).

One combination of three independent data sets is the triple of ASCAT soil moisture retrievals, AMSR-E retrievals obtained with the LPRM model, and a modelled soil moisture data set such as the one using the Noah model of the Global Land Data Assimilation System (GLDAS). DORIGO et al. (2010) applied the triple collocation method to the anomaly time series (actual 


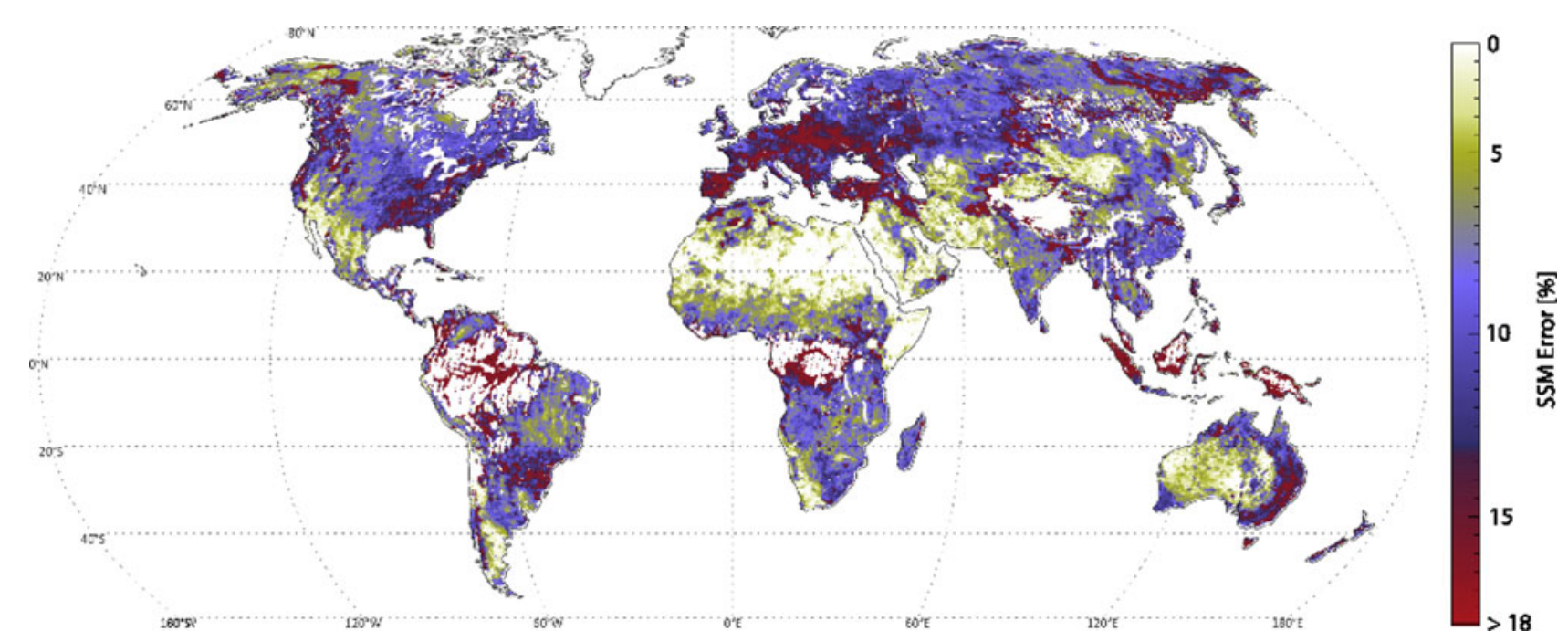

Figure 9: Spatial error field of the ASCAT soil moisture product obtained by applying the triple collocation technique to ASCAT, AMSR-E and GLDAS soil moisture data. The figure is based upon methods presented in DORIGO et al. (2010).

observation versus the seasonal mean values) of these three data sets. The resulting estimate of the error of the ASCAT anomalies is shown in Fig. 9. One finds that the estimated errors of the anomalies are somewhat larger than the errors of the absolute values as obtained by error propagation (Fig. 6), but overall, the spatial patterns are comparable. In particular the influence of global vegetation patterns on the errors is apparent.

\section{Emerging applications}

The use of a new data type in applications is usually very challenging, simply because models are built around input data that were available at the time when the models were developed. Accordingly, it is in general necessary to adjust the models in order to be able to make effective use of the new type of data. This process usually takes many years, and even though the first global soil moisture data set derived from the ASCAT predecessor ESCAT was already released in 2002 (SCIPAL et al., 2002), the development of applications for the ASCAT soil moisture products is only in its beginning. In the following, several of the emerging applications of the ASCAT soil moisture data will be discussed, reviewing published applications studies for ESCAT and ASCAT and presenting some results of the authors for a better illustration of the challenges and the potential of using this new data type.

\subsection{Numerical Weather Prediction}

Reasons to use soil moisture data in Numerical Weather Prediction (NWP) are manifold. Soil moisture is influencing near surface parameters by affecting the exchange of heat and water between the soil and the lower atmosphere (FERRANTI and VITERBO, 2006; DHARSSI et al., 2011). To raise forecast quality, knowledge of soil moisture distribution is therefore of crucial interest for NWP (SEUFFERT et al., 2002). Concerning precipitation, especially the feedback processes between increase of evapotranspiration and amplification of precipitation (SCHÄR et al., 1999) are of major interest. Though knowing the need for proper soil moisture representation, simplifications in the modelling of land-surface processes in forecasting models due to technical requirements lead to systematic errors in the modelled soil moisture field (SCIPAL et al., 2008a), degrading forecast quality. Assimilation of satellite soil moisture measurements might help to overcome this weakness. For example, the assimilation of bias corrected soil moisture measurements with nudging (SCIPAL et al., 2008a; DHARSSI et al., 2011) proved to be a valuable tool for global models mainly in tropical regions, whereas for mid-latitudes the effect is described as neutral. On a regional scale, MAHFOUF (2010) assimilated globally bias-corrected ASCAT data with a simplified Extended Kalman Filter (sEKF) and focused mainly on forecasts of $2 \mathrm{~m}$ temperature and humidity, showing some improvement for bias over Central Europe. ZHAO et al. (2006) investigated the impact of ESCAT SWI for precipitation forecasts in China with a technical simple approach, nevertheless improving forecasts.

In the study briefly presented here, the impact of soil moisture assimilation on rainfall forecasts, especially convective precipitation in complex terrain was investigated. The limited area model ALADIN-AUSTRIA (WANG et al., 2006; WANG et al., 2011), which is the operational NWP system at the Austrian Met-service ZAMG, has been used for the experiments. The model has a horizontal grid point spacing of 9.6 kilometres and 60 vertical levels, the global coupling model is Météo Frances ARPEGE. The model domain is covering large parts of Central Europe. For the offline assimilation of the ASCAT soil moisture, the SEKF of MAHFOUF (2010) has been used. To test the influence of the 


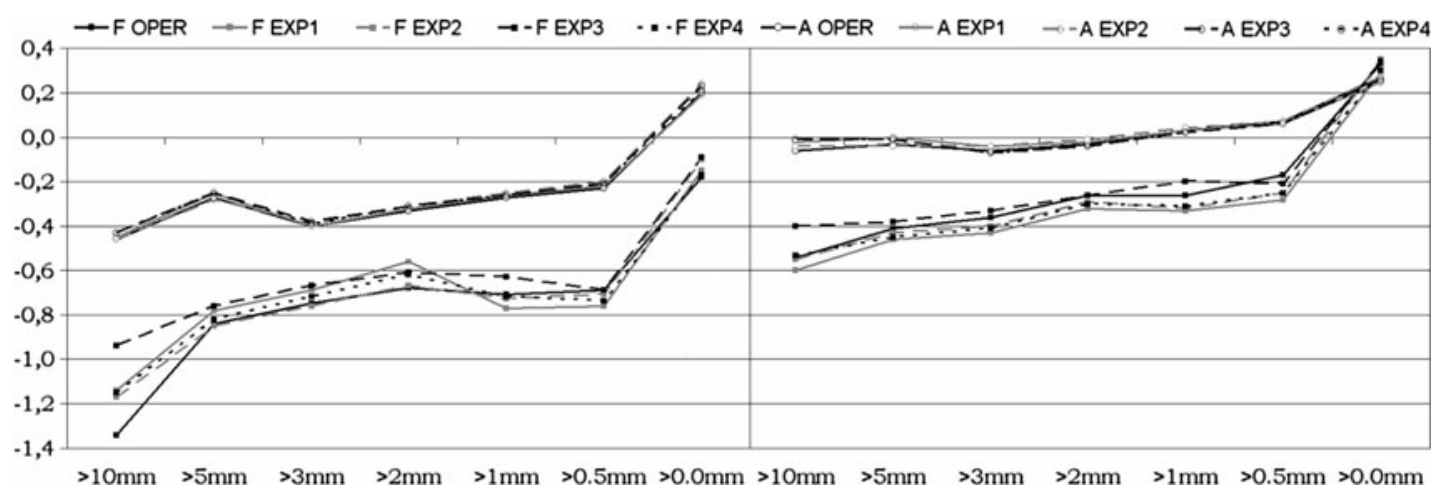

Figure 10: A (left) and S (right) score for ALADIN precipitation forecasts without (OPER) and with (EXP1-4) assimilation of soil moisture in Austria during July 2009. Verification is separated for a flatland (F) and an Alpine (A) region as well as for precipitation events with different mean areal precipitation, analyzed by INCA (abscissa). The ordinate is indicating values for A and S, where 0 indicates a perfect forecast.

different quality flags (see Section 3.5 ) provided with the data set and the CDF matching (Section 4.1), several experiments have been carried out. Both a global and a local CDF matching were applied to the data set. The global approach was chosen as the available data set of just 14 months is relatively short for CDF matching. The resulting regression equation is comparable to the findings in MAHFOUF (2010). The local approach was tested as the retrieval algorithm for ASCAT is calculated independently for each grid point without taking into account information from surrounding points. Therefore, each of them should be compared separately to the corresponding ALADIN grid point forecasts. Besides this, model bias tends to have a spatial variability (REICHLE et al., 2004) which is taken into account using this single grid point approach (but not with the global one).

Forecast runs for July 2009 have been verified for Austria using the so-called SAL approach (WERNLI et al., 2008). For verification high resolution precipitation analysis data from the INCA system (HAIDEN et al., 2011) are available from this region. Overall, soil moisture assimilation for this summer month had a positive impact for lowlands (see Fig. 10) both for the A (amount of precipitation) and S score (areal structure of the precipitation cells). For complex terrain a more or less neutral impact was found. This leads to the conclusion that in mountainous regions, orographic features are playing an important role in the localisation of convective initiation, while in lowlands the more stochastic nature of initiation is benefitting from the improved soil moisture distribution in the ground. Moreover, the local bias correction (EXP3 and EXP4) seems to be favourable compared to the global one (EXP2) as well as to no bias correction at all (EXP1) for ASCAT input (Fig. 10).

Another feature revealed by the investigations is an improvement of the modelled deep soil moisture due to assimilation. Although only superficial soil moisture is measured by ASCAT, the soil model within ALADIN is using this information for water exchange in the ground, showing a positive impact compared to an
Austrian in situ measurement station (not shown). Furthermore, forecasts of relative humidity at $2 \mathrm{~m}$ can be improved due to the assimilation during the first six hours of the model run, and overall, forecasts tend to be cooler and moister when assimilating soil moisture in comparison to Austrian SYNOP stations which has a positive impact on model bias during night-time. These are promising results, showing the value of ASCAT soil moisture assimilation in a NWP model.

\subsection{Runoff forecasting}

Accurate flood forecasts rely on appropriately estimated current hydrological conditions at the time of the forecast. As it plays an important role in partitioning rainfall into runoff and infiltration, soil moisture is one of the key variables in flood forecasting models. Unfortunately, soil moisture is very difficult to measure at the scales of hydrologic interest. Ground based measurements of soil moisture are usually performed for individual soil profiles at a number of locations within a catchment (WESTERN et al., 2002). It is difficult to cover large areas by the sensors due to logistic constraints, and the spatial support or footprint of one measurement is usually only a few centimetres (GRAYSON and BLÖSCHL, 2000). This makes it very difficult to estimate meaningful spatial averages over catchments from in-situ measurements. An alternative to ground based soil moisture measurements is the use of remote sensing methods. The main advantage of spaceborne sensors is that they provide an integral value over an area rather than point values and most of the data are available at a global scale. However, spaceborne sensors have relatively large footprints (or pixel sizes) relative to the hydrological processes of interest, relatively low repeat cycles (typically one or a few days) relative to the soil moisture dynamics and, perhaps most importantly, limited penetration depths of the microwave signal into the ground of a few centimetres or less. Similar scale inconsistencies apply when comparing space borne data 
22.6.2009 9 a.m.
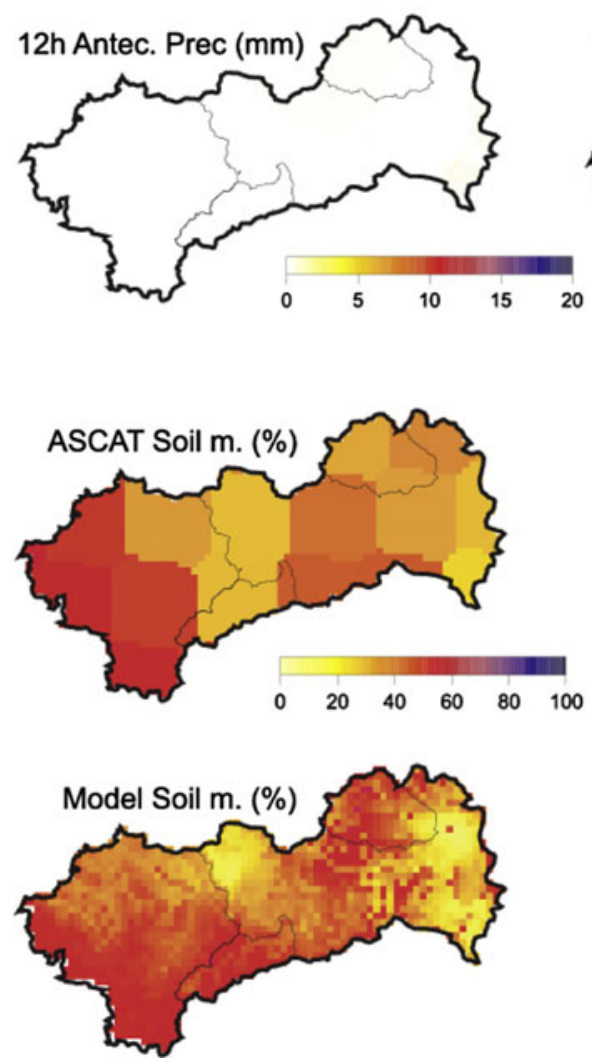

23.6.2009 7 p.m.
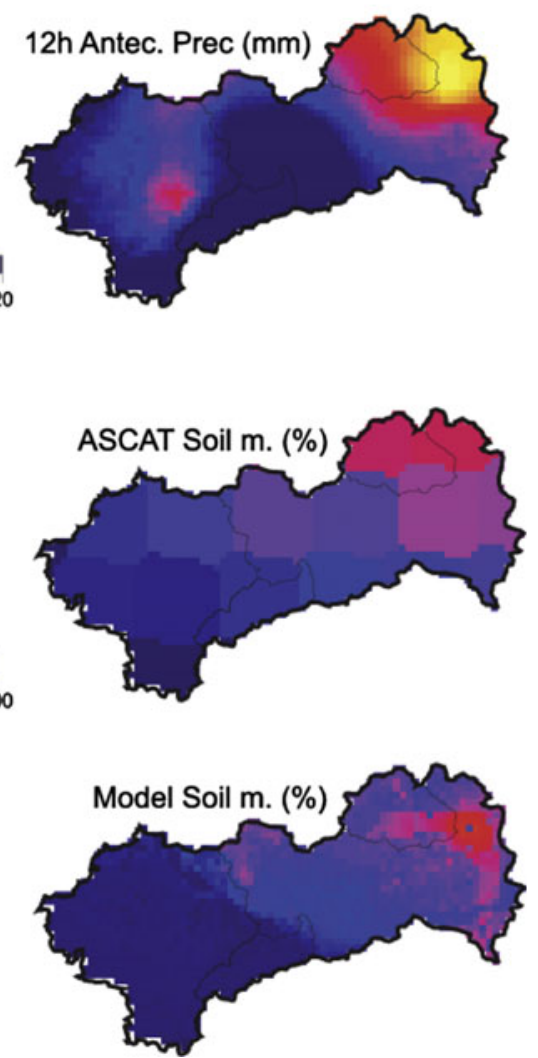

Figure 11: Top: Antecedent rainfall during the past 12 hours, Centre: remotely sensed ASCAT surface soil moisture, Bottom: Simulated skin soil moisture in the Kamp catchment $\left(1550 \mathrm{~km}^{2}\right)$. Left: 22 June 2009 immediately before a 5 year flood. Right: 23 June 2009 during the flood.

with hydrological models but limited penetration depth are usually dealt with by using a skin layer soil moisture model (GEORGAKAKOS UND BAUMER, 1996). An example for the simulated skin soil moisture and remotely sensed ASCAT surface soil moisture patterns for different dates (before and during a flood event) at the Kamp catchment in north-eastern Austria is given in Fig. 11.

In regions without adequate hydro-meteorological monitoring networks, like wide parts of the African continent, satellite based soil moisture estimates provide important information for water management issues. Particularly for large river systems remotely sensed soil moisture may serve as an useful indicator for runoff dynamics. SCIPAL et al. (2005) analysed the predictive quality of ESCAT based SWI data in relation to observed runoff data at Zambezi river in Africa. High correlations $\left(r^{2}>0.85\right)$ between observed discharge and spatially averaged SWI values at large basins $\left(>10,000 \mathrm{~km}^{2}\right)$ show the potential of scatterometer soil moisture products for hydrological water management tasks. The good predictive ability of SWI values for the prediction of runoff response for lead times in the order of 10 days up to several weeks at large catchments is also supported by studies in South Africa (VISCHEL et al., 2008) and the Zambezi (MEIER et al., 2011). However, if one moves towards smaller catchments the hydrologic response to meteorological forcing gets much quicker; hydrological rainfall-runoff models with diverse complexities are therefore needed to simulate the runoff generation processes.

With increasing complexity of the hydrological models the identification of appropriate model structure and parameters becomes also more important. As hydrological models are usually calibrated against runoff only, the benefit of additional information about internal model states, particularly soil moisture, may help to constrain uncertainties in model structure and parameters. A study for 148 small to medium catchments in Austria by PARAJKA et al. (2009) showed that multi-objective calibration, based on ESCAT soil moisture and observed discharge measurements, provided more robust model parameters than using either of these two sources. The advantage of realistic parameters is the ability to describe extraordinary situations which are not included in the calibration data sets.

Another way to use remotely sensed soil moisture data to support runoff predictions is the estimation of antecedent soil moisture conditions. BROCCA et al. (2009) tested the ability of ESCAT based SWI values to estimate antecedent wetness conditions for an event 


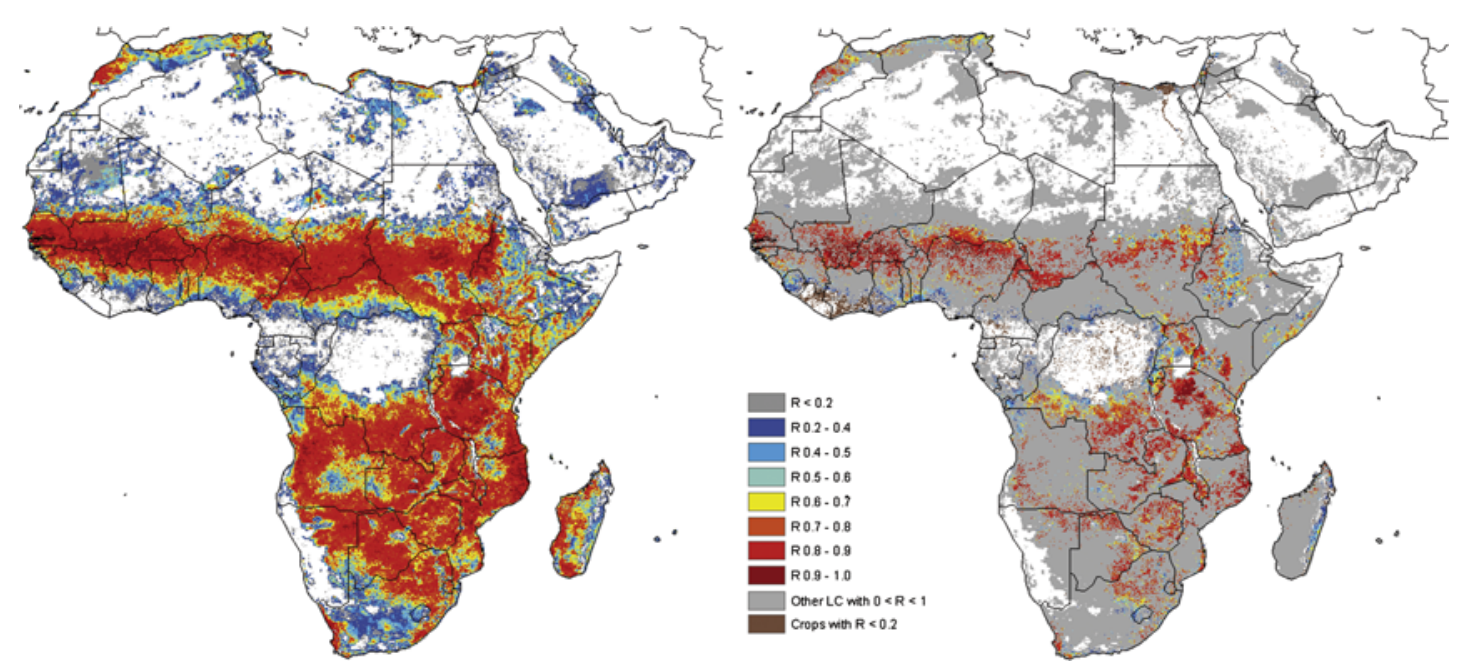

Figure 12: Correlation between monthly SWI and NDVI time series over Africa for all land cover classes (left) and for cropping areas only (right).

based rainfall-runoff model at different catchments (ranging from 137 to $165 \mathrm{~km}^{2}$ ) in Italy. Compared to commonly used wetness indices like antecedent precipitation and observed base flow, the SWI based method to estimate the runoff gave the best model efficiencies (NSME > 0.94). The potential of remotely sensed soil moisture to estimate antecedent soil moisture conditions is also indicated by the results of MATGEN et al. (2012b). For a well monitored experimental catchment in Luxembourg ASCAT SWI data were found to be a good proxy for abrupt switches in river system dynamics.

However, operational flood forecasting models are usually based on continuous soil moisture accounting schemes to appropriately estimate initial soil moisture conditions. A recent development is the involvement of data assimilation techniques to reduce the uncertainty of the antecedent soil moisture states. In hydrology the most popular assimilation techniques are sequential updating schemes like Ensemble-Kalman-filtering or Particle filtering. While the real time assimilation of discharge measurements into operational flood prediction systems is a widely accepted, the relative value of assimilating remotely sensed soil moisture into operational flood prediction models is yet difficult to be quantified (MATGEN et al., 2012a). Different remotely sensed soil moisture products are used along with various hydrologic models, ranging from physically based approaches to simple conceptual models. However, the results of some data assimilation experiments based on ASCAT soil moisture data indicate that the assimilation of the ASCAT SWI, representing the root zone soil moisture, potentially improves flood predictions, particularly in case of highly uncertain initial soil moisture conditions (BROCCA et al., 2010b). The positive impact of assimilating ASCAT surface soil moisture into hydrological models with an explicit description of the surface soil moisture seems to be smaller compared to the assimilation of SWI into the root zone layer (BROCCA et al., 2012a). Much more research is still needed to understand the benefits and limitations of remotely sensed soil moisture for hydrologic prediction, but in any case much progress can be expected from the increasing availability and quality of soil moisture data from ASCAT and other microwave sensors.

\subsection{Vegetation and Crop Growth Monitoring}

The root zone moisture supply is one of the main factors limiting plant growth, particularly in arid, semi-arid and temperate climatic zones. Therefore, the moisture content in the soil profile is one of the most important parameters for monitoring and predicting the growth of natural vegetation and non-irrigated agricultural crops. With respect to the capability of scatterometers for monitoring of natural vegetation, GOUVEIA et al. (2009) compared SWI time series with Normalised Difference Vegetation Index (NDVI) data as derived from images acquired by the VEGETATION instrument over Portugal. They found that both parameters are closely related and, together, the SWI and NDVI could be used for describing the spatial extent, severity and persistence of drought episodes over Continental Portugal, from 1999 to 2006. The relationship between SWI and NDVI was exploited by ZRIBI et al. (2010) who developed a methodology to predict the next-month's NDVI based on this-month's NDVI and SWI values over the Kairouan plain, a semiarid region in Tunisia. To illustrate how these two parameters are related over larger domains, Fig. 12 shows the correlation of monthly NDVI and SWI time series over Africa for the years 2007 to 2009 . One can see that the correlation is strong in regions with a strong seasonal vegetation cycle, while over deserts and tropical forest the two variables are not correlated as expected. Of particular relevance for drought assessment is that in Africa agricultural areas are predominantly found in those regions where the correlation between SWI and NDVI 
is good. This illustrates the potential of ASCAT for modelling crop yield.

To simulate growth and yield of individual crops more quantitative approaches are needed. Crop simulation models are tools especially used to describe the impact of climatic and weather conditions and management strategies on crop growth and yield at field scale. But they can equally be applied in a distributed model at regional scale (DE WIT and VAN DIEPEN, 2007). Regional crop model applications are however often uncertain due to the limited availability and quality of spatial model input data. The most promising method for estimating crop yield over regions more accurately is therefore to combine ecosystem models and remote sensing data (DE WIT and VAN DIEPEN, 2007; VERSTRAETEN et al., 2010). Especially precipitation, soil input data and related soil water content variations need to be considered, because of their importance for soil water storage and water availability for crops (EITZINGER et al., 2008). Since most models integrate at daily time steps, daily weather data are required as input data, consisting of at least maximum and minimum temperature, solar radiation as well as precipitation. To study the applicability of ASCAT for regional yield monitoring in Austria the dynamic crop growth and yield model DSSAT (HOOGENBOOM et al., 2004) was applied in the case study region of "Seewinkel", which is one of the driest and warmest regions in Austria. First results show good agreement of the course of daily measured and simulated soil moisture with the ASCAT $25 \mathrm{~km}$ products (not shown). The results point directly to one of the most significant advantages of ASCAT soil moisture data which should be used for improving spatial crop yield modelling: The use of information on spatial variability of top soil moisture as crop model input could improve the spatial crop yield simulations as compared to the use of the point information of single weather stations.

\subsection{Epidemic risk assessment}

Soil moisture data can be used for modelling infectious diseases forced by weather and environmental parameters, particularly mosquito-borne diseases (MONTOSI et al., 2012). Mosquito-borne diseases have always been a serious public health issue for people and their livestock in tropical and subtropical regions. Under recent global warming, however, mosquito-borne disease outbreaks are also observed in mid-latitudes more frequently. Changing climate- and environmental parameters affect not only the geographical expansion of mosquito species, but also contribute to an increase of the vector competence of local mosquitoes.

So far, ASCAT soil moisture data have not been used for epidemic risk assessment. Here, initial results for assessing the risk for Bluetongue virus in Austria are shown. The Bluetongue virus (BTV) gained public attention due to economical losses of $150 \mathrm{M} €$ (HOOGENDAM,
2007) caused by the first outbreak of BTV serotype 8 in North-western Europe in 2006 (CONRATHS et al., 2009). The BTV is circulating in a natural transmission cycle between vectors (small mosquitoes, so-called biting midges) and hosts (ruminants, mainly cattle, sheep and goat). Thus, for risk assessment the knowledge of both the vector- and the host density is of fundamental importance. Unfortunately, the density of the main vector, i.e. the midge species Culicoides obsoletus, is usually unknown, but it may e.g. be estimated by a logistic regression equation using temperature, precipitation and soil moisture fields. Regression coefficients were calculated using cross-correlation maps for daily temperature, precipitation and soil moisture measurements versus midge counts observed at the University of Veterinary Medicine Vienna (JUNGBLUT and SCHOBER, 2011). The midge density was adjusted for host numbers following the findings of GARCIA-SAENZ et al. (2011). The meteorological input data can be taken from observations, NWP models or satellite measurements. In our study we used temperature and precipitation forecasts from the Austrian meso-scale NWP model ALADIN (WANG et al., 2011) and ASCAT soil moisture interpolated to a $10 \mathrm{~km}$ grid.

Having estimates of the spatio-temporal distribution of the vectors and the hosts allows calculating risk maps. In epidemiology, the risk for a disease outbreak is specified by the basic reproduction number $\mathrm{R}_{0}$. It is a measure for the number of secondary cases caused by one single case in a completely susceptible population (at the beginning of an epidemic). Thus, a major disease outbreak may only occur for $R_{0}>1$. An analytical solution for $\mathrm{R}_{0}$ is usually derived from epidemic differential equation models. Here we applied the formula according to HARTEMINK et al. (2009) and GUIS et al. (2012). Fig. 13 depicts as examples mean $\mathrm{R}_{0}$ maps for June, July, August, and September 2010. While red areas indicate a potential risk for a BTV outbreak $\left(\mathrm{R}_{0}>1\right)$, green areas are associated with no risk at all $\left(\mathrm{R}_{0}<1\right)$. The $\mathrm{R}_{0}$ values for July are within the range $0.45-4.41$, in which the maximum indicates that from one infected animal on average 4.41 animals may be newly infected with BTV.

Population dynamics of midges are correlated to meteorological input data back to one month (JUNGBLUT and SCHOBER, 2011). Therefore risk assessments allow a prediction up to one month into the future; the $\mathrm{R}_{0}$ maps depict a seasonal cycle with maximum risk in July and August. A verification of the $\mathrm{R}_{0}$ maps is currently not possible because, fortunately, so far no major BTV outbreaks occurred in Austria. However, a first BTV positive farm was detected in November 2008 north of Salzburg, the region with maximum $\mathrm{R}_{0}$ values (Fig. 13). The presented risk assessment may also be applied to other pathogens spread by biting midges, like the African Horse sickness virus or the Schmallenberg virus. The latter emerged in Germany and the Netherlands for the first time in 2011 (HofFMANN et al., 2012) and is expected to cause some economic losses in 2012. 

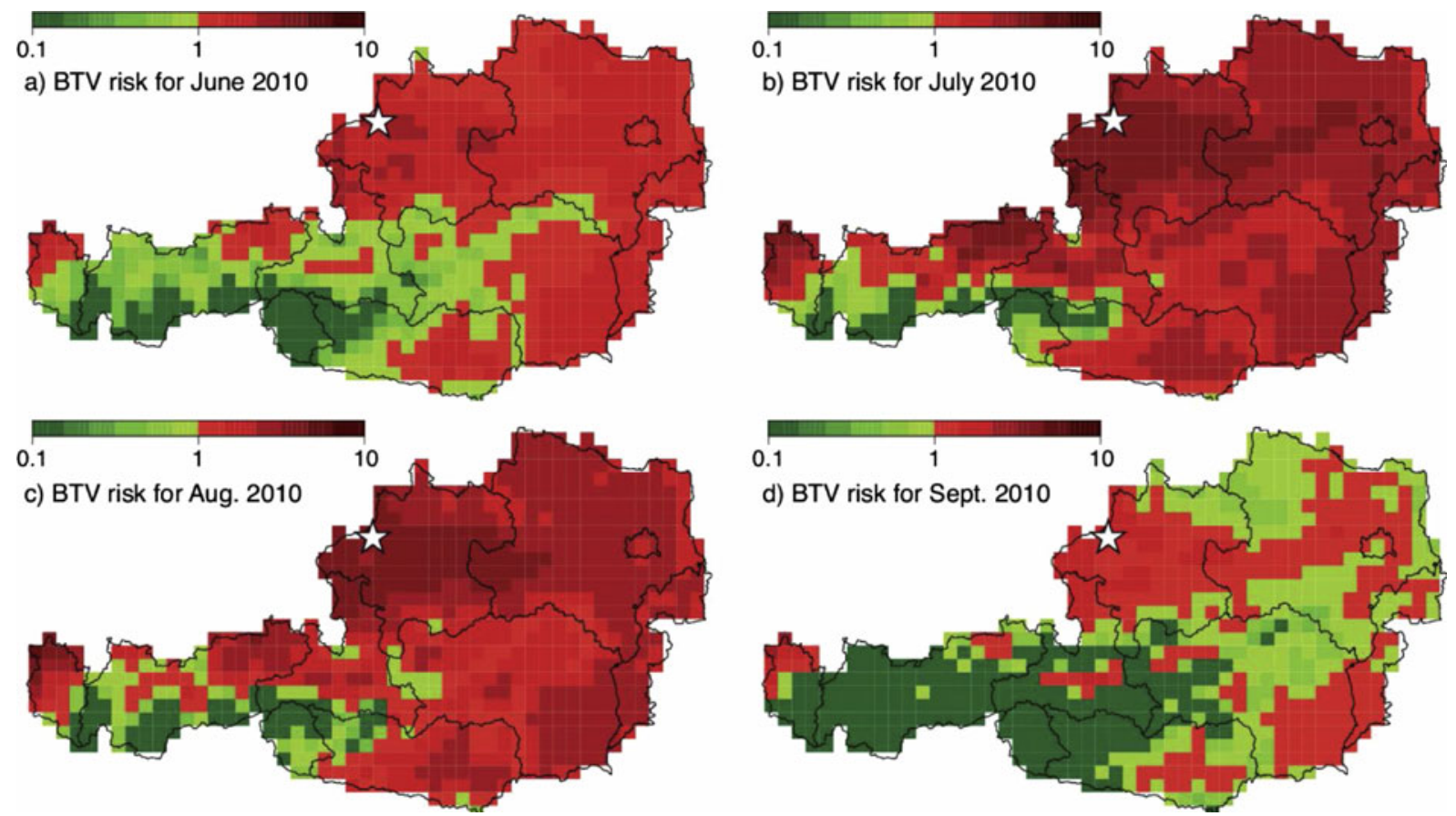

Figure 13: Mean daily basic reproduction number R0 for June to September 2010, depicting the spatio-temporal distribution of the potential risk for a bluetongue virus (BTV) outbreak in Austria. Green colours depict regions at minor risk, red at moderate risk and dark red at high risk. The location of the first BTV cases confirmed in Austria is marked by a white asterisk.

\subsection{Societal risk assessment}

For a natural event to become a disaster, humans - or rather society or a social system with all its components - have to be adversely affected to a considerable degree (EEA, 2010). In this context risk analysis includes the assessment of threats that a natural hazard poses to an exposed social system and of the potential impacts it could cause. For that purpose the event itself has to be modelled, including main characteristics like probability, frequency and magnitude, as well as spatial and temporal dynamics. In addition to that, the exposed and potentially affected social system has to be assessed, both in terms of its general structure (e.g., spatial distribution of population and infrastructure), as well as for its adaptive and coping capacity which after all define the system's vulnerability and resilience (BIRKMANN, 2007). In recent years, integrative approaches for the analysis of multiple risk factors have been applied in order to further increase the consideration of socioeconomic factors in natural hazards and disaster management. Vulnerability is a strongly interdisciplinary concept that considers inherent aspects of an exposed human system including e.g. social, economic, cultural, and institutional characteristics.

Risk assessment for water related hazards does not only include the identification and monitoring of certain environmental conditions, but also strongly considers potential impacts on population, infrastructure, and the society in general (AUBRECHT et al., 2010). Excessive water and water scarcity can both have strong influence on a social system. Too much precipitation or fast snowmelt can very quickly saturate the soil in a catchment area leading to increased surface water runoff and eventually resulting in wide-area flooding. In case such conditions prevail for a longer time, water excess influences vegetation growth and facilitates the distribution of vector-borne diseases. Water shortage on the other hand can result in a rapid decrease of soil water storage. Subsequent dry periods influence agricultural productivity, limit the availability of fresh water for both general public and industry, and last but not least significantly increase the probability of wildfires through drought and vegetation stress (GOUVEIA et al., 2009). Longerlasting drought periods can permanently destroy cultural landscapes and lead to land degradation. Integration of satellite based soil moisture information on regional level enables analysis of potential relationships between anomalous soil conditions and increased incidence rates of natural hazards such as flooding and drought events, the latter being e.g. directly related to wildfire occurrence (XIAO and ZHUANG, 2007).

Wildfires and its spatial patterns have been set in relation with soil moisture conditions for various case studies in different regions of the world such as Canada's Northwest Territories (LEBLON et al., 2002), Alaska (KASISCHKE et al., 2007), Siberia (BARTSCH et al., 2009a) and Africa (AUBRECHT et al., 2011). In the latter study that we briefly highlight here, monthly aggregated fire products for 2009, derived from the Operational Linescan System (OLS) on board the U.S. Defense Meteorological Satellite Program (DMSP) were spatially compared to ASCAT SWI data. The year 2009 was identified as an 
extreme year for the African continent, characterized by unusually low cumulative rainfall that caused particularly intense dry periods between the months of March and June. The northern Sahel region and eastern Africa were especially affected. Primary result of the integrative analysis is the detection of general (seasonal) spatial correlation patterns between dry areas and regions affected by wildfires. A closer examination whether anomalously dry soil conditions significantly favour fire development as illustrated in previous studies for Siberian forest fires (JuPP et al., 2006) shows that at least for the year under consideration exceptional dry conditions were not a necessary precondition for fire occurrence in Africa, since already the 'regular' dry periods were effectual in that sense. This illustrates that there is no simple relationship between fires and soil moisture as other factors such as the amount of biomass that can serve as fuel for the fires need to be accounted for as well.

Opposite to that, excessive water showed its impact in various examples in the recent past. How far climate change had and will impact on the frequency and magnitude of floods is still unclear, which is due to the lack of instrumental records and confounding effects of changes in land use and engineering (IPCC, 2012). The Pakistan floods of July to September 2010 hit the country over a period of several weeks. The number of people affected was 20.2 million of whom about 2000 people were killed, making it one of the worst natural disasters ever experienced in the country. Through the application of freely available global datasets and different satellite-data derived flood masks (e.g. from MODIS, Landsat etc.) an impact assessment on population, land cover and infrastructure was carried out. LandScan data for population estimates (Fig. 14), data on infrastructure from OpenStreetMap, and Globcover for land cover were compiled and estimated impacts quantified (FLEISS et al., 2011). It was concluded that the assessment of impacts showed that although there are suitable public data available for post-disaster assessment, the accuracy of the results relies on data quality as well as the methodological approach used for the assessment. Furthermore, it was highlighted that clear definitions for the impact assessment are also needed for a better interpretation of the results.

Additionally, SWI data and associated anomalies were applied to assess the hydrological root causes of the flood and if such data are suitable for early warning purposes. FLEISS et al. (2011) concluded that the SWI can be suitable to identify root causes for the 2010 Pakistan floods (Fig. 14), by depicting the unusual precipitation pattern in the Indus region well. Limitations in the use of the ASCAT data as an element of an early warning system for floods arise from the need to further investigate the Monsoon pattern as well as the response characteristics of the river basin (e.g. impacts of high topography and snow coverage on data quality).

The highlighted applications in the context of drought and flood showed that globally available, homogenous and continuously updated soil moisture data are an important factor for the effective assessment and monitoring of risk related processes. Opportunities arise to observe the development of extreme events and to possibly identify thresholds for early warning. In that case information on thresholds for the hazard (such as saturation or dryness of soil) has to be combined with vulnerability factors reflecting susceptibility and the lack of resilience of the society, in order to allow assessing the risk and associated potential impacts.

\section{Conclusions and outlook}

The ASCAT soil moisture product can be regarded as an example that, often, science does not proceed along predetermined pathways. Being an active sensor operated in C-band, ASCAT has often been held to be sub-optimal for soil moisture mapping because of its higher sensitivity to surface roughness and vegetation compared to passive L-band sensors (KERR, 2007). The view that there is a relatively sharp distinction between sensors operating at different wavelengths was recently expressed by ENTEKHABI et al. (2010a) who wrote that “... L-band retrievals can be performed and meet the science requirements. In contrast, $\mathrm{C}$ - and $\mathrm{X}$-band measurements are representative of the top $1 \mathrm{~cm}$ or less of soil. Moderate vegetation (greater than $\sim 3 \mathrm{~kg} \cdot \mathrm{m}^{-2}$ ) attenuates the signal sufficiently at these frequencies to make the measurements relatively insensitive to soil moisture." However, as this review shows, the validation results for ASCAT have overall been quite positive, with ASCAT performing equally well, and over some regions like Europe even somewhat better than the initial SMOS- and best AMSR-E soil moisture retrievals. Of course, there are also situations where the quality of the ASCAT retrievals is problematic, e.g. over mountainous regions or over some desert areas where, for the time being, it might be better to use the SMOS or AMSR-E retrievals.

Nevertheless, the conclusion from this review is that regarding C-band as "sub-optimal" for the task of soil moisture retrieval falls short of explaining many of the results obtained for ASCAT so far. In particular, this review highlighted the important role of other sensor characteristics - most importantly radiometric accuracy, multiple-viewing capabilities and spatio-temporal coverage - that make ASCAT a suitable sensor for soil moisture monitoring. It is therefore recommended not to just think in terms of the wavelength range where the sensitivity of the measurements to soil moisture is maximised, but rather to consider the signal-to-noise ratio of a sensor. And given that the antenna beam width and wave spreading losses increase when moving to longer wavelengths (UlABY et al., 1982), it is not clear whether for a given spatial resolution (e.g. $25 \mathrm{~km}$ ) the practically achievable signal-to-noise ratio is much worse for sensors operating in $\mathrm{C}$ - or even $\mathrm{X}$-band than for sensors operating in L-band. This question needs to be addressed in future studies that analyse and compare the end-to-end error budgets of ASCAT, AMSR-E, SMOS, SMAP and other 
a)

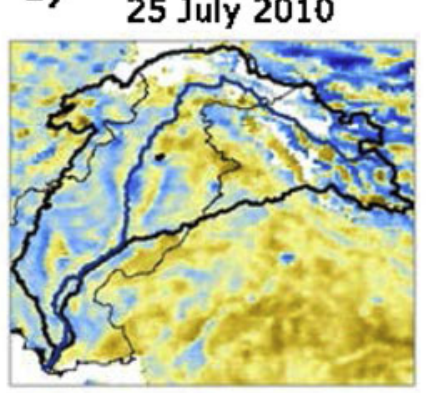

5 August 2010

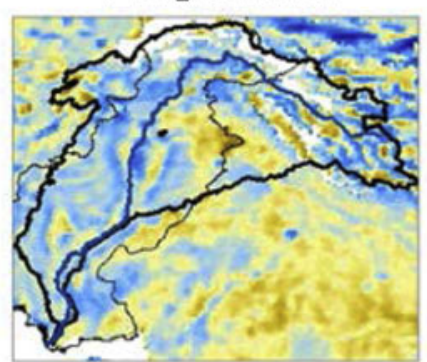

15 August 2010

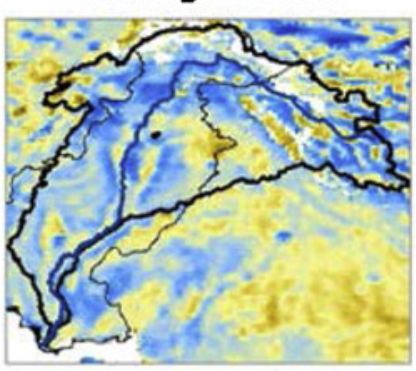

SWI Anomaly

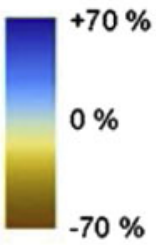

b)

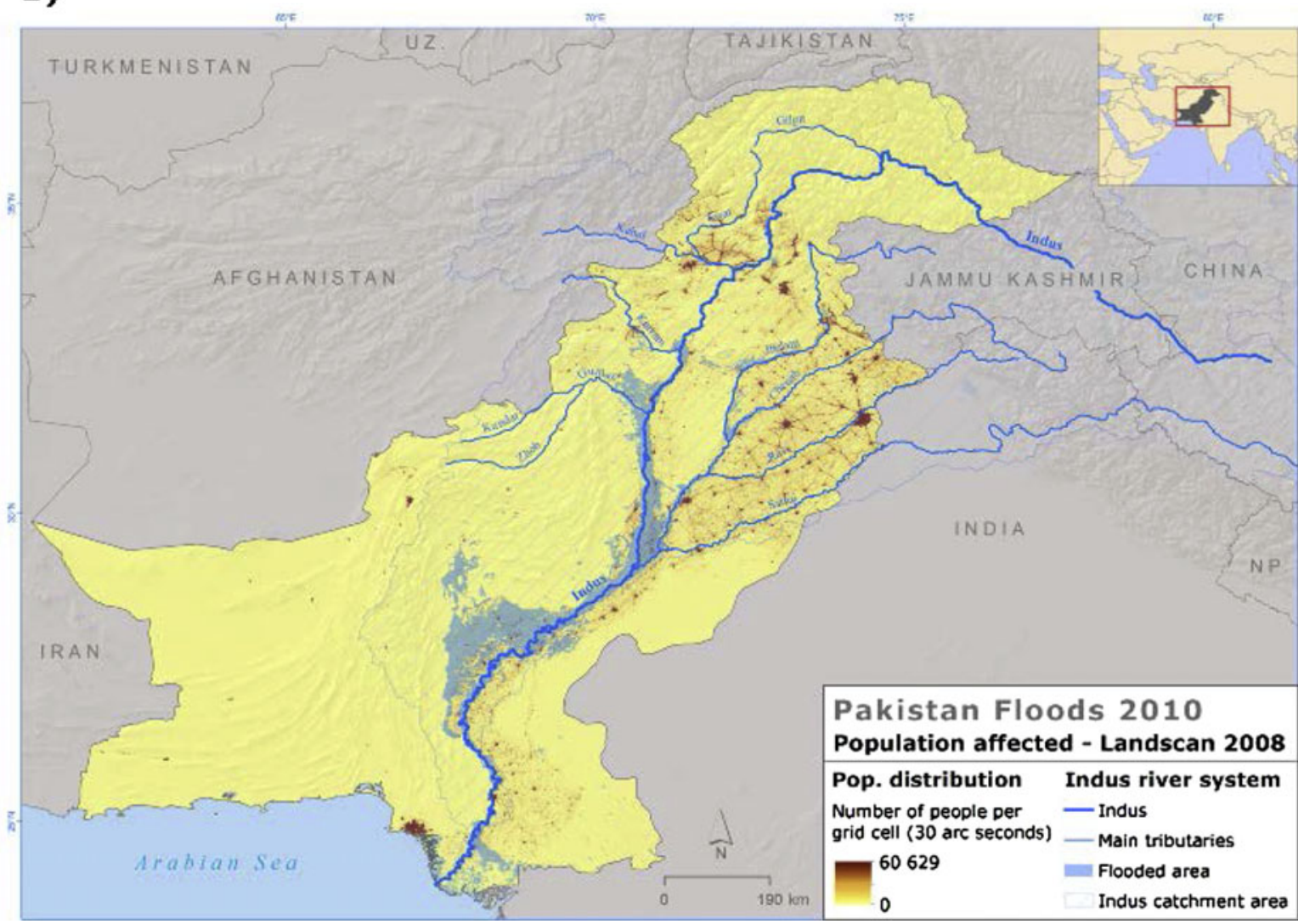

Figure 14: SWI anomaly within the Indus river basin (a) and a map of the population affected by the 2010 Pakistan Floods (b). From FLEISS et al. (2011).

microwave sensors in order to better understand their respective advantages and disadvantages. A better understanding of sensor performances will also open the door for new innovative approaches for merging the different data sets in order to improve the overall product accuracy and the spatio-temporal coverage (LIU et al., 2011).

This review has also shown that the uptake of the ASCAT soil moisture data in application is not straight forward due to the fact that, in general, available models need to be adapted before it is possible to use remotely sensed soil moisture data either as input, for calibration or for assimilation. Also, the quality of the ASCAT soil moisture product varies in space and time which means that users need to build up expert knowledge in order to select only those ASCAT soil moisture values which are fit for use in their applications. This has for example been an important element of a recent study carried out by TAYLOR et al. (2012) who could show based on soil moisture observations from ASCAT and AMSR-E that afternoon rainfall preferentially falls over soils that are dry compared to their surrounding area. Mechanistically, their result can be explained by enhanced moist convection over dry soils and/or meso-scale variability in soil moisture, yet this negative soil moisture feedback was not correctly modelled by six state-of-the-art global weather and climate models. The study by TAYLOR et al. (2012) thus illustrates how satellite based soil moisture retrievals, despite their limitations and caveats, can be used to gain new insights into natural phenomena. 
Considering the initial challenges when starting to use ASCAT soil moisture data in a particular application, the progress made in the various application domains is very promising. In particular in numerical weather prediction and hydrologic forecasting positive impacts of assimilating the ASCAT soil moisture data have already been demonstrated (BROCCA et al., 2010b; DHARSSI et al., 2011). In other application domains such as vegetation and crop yield monitoring, epidemic risk modelling and societal risks assessments some first encouraging results have been obtained, but much further work is required to optimally use the information provided by ASCAT. With the increasing availability of soil moisture data also from other sensors (SMOS, SMAP, AMSR-E, etc.) it can be expected that we will see rapid progress in the application of these global soil moisture data sets in the next decade.

\section{Acknowledgments}

We gratefully acknowledge the support of the Austrian Space Applications Programme (ASAP) through the project "Global Monitoring of Soil Moisture for Water Hazards Assessment (GMSM)" (http://www.ipf.tuwien.ac.at/ gmsm/), of EUMETSAT through the "Satellite Application Facility on Support to Operational Hydrology and Water Management (H-SAF)" (http://hsaf.meteoam.it/), of the $7^{\text {th }}$ Framework Programme of the European Commission through the GMES project "geoland2" (http:// www.gmes-geoland.info/), and of the Austrian Science Fund (FWF) through the Vienna Doctoral Programme on Water Resource Systems (http://www.waterresources.at/, DK-plusW1219-N22).

\section{References}

Albergel, C., C. RÜdiger, T. Pellarin, J.-C. Calvet, N. Fritz, F. Froissard, D. Suquia, A. PetitPa, B. Piguet, E. MARTIN, 2008: From near-surface to root-zone soil moisture using an exponential filter: an assessment of the method based on in-situ observations and model simulations. - Hydrol. Earth Sys. Sci. 12, 1323-1337.

Albergel, C., C. RÜdiger, D. Carrer, J.-C. Calvet, N. FritZ, V. NAEIMI, Z. BARTALIS, S. HASENAUER, 2009: An evaluation of ASCAT surface soil moisture products with in-situ observations in Southwestern France. - Hydrol. Earth Sys. Sci. 13, 115-124.

Albergel, C., J. C. Calvet, P. De Rosnay, P. Balsamo, W. Wagner, S. Hasenauer, V. Naeimi, E. Martin, E. BAZILE, F. BouYsSEl, J. F. MAHFOUF, 2010: Crossevaluation of modelled and remotely sensed surface soil moisture with in situ data in Southwestern France. Hydrol. Earth Sys. Sci. 14, 2177-2191.

Albergel, C., P. De Rosnay, C. Gruhier, J. MuñozSABATER, S. Hasenauer, S. IsAKSEn, Y. KerR, W. WAGNER, 2012: Evaluation of remotely sensed and modelled soil moisture products using global groundbased in situ observations. - Rem. Sens. Environ. 118, 215-226.

Anderson, C., J. Figa, H. Bonekamp, J. W. Wilson, J. VerspeeK, A. Stoffelen, M. Portabella, 2012: Validation of backscatter measurements from the advanced scatterometer on MetOp-A. - J. Atmos. Oceanic Technol. 13, 29-88.

Attema, E., F. Ulaby, 1978: Vegetation modeled as water cloud. - Radio Sci. 13, 357-364.

Aubrecht, C., S. KienBerger, K. Steinnocher, P. Zeil, 2010: Assessment of vulnerability to water hazards - A concept for broad-scale information integration. GI_Forum'10 Workshop: Spatial assessment and analysis of vulnerability, Salzburg, Austria.

Aubrecht, C., C. D. Elvidge, K. BAugh, S. Hahn, 2011: Identification of wildfire precursor conditions: Linking satellite based fire and soil moisture data. - in: J. M. R. S.a. N. J., R. M. TAVARES (Editor), Computational Vision and Medical Image Pro-cessing: VipIMAGE 2011. - Taylor \& Francis, CCR Press, 347-353.

BARTALIS, Z., K. SCIPAL, W. WAGNER, 2006: Azimuthal anisotropy of scatterometer measurements over land. IEEE Transactions on Geoscience and Remote Sensing. 44, 2083-2092.

Bartalis, Z., W. WAgner, V. Naeimi, S. Hasenauer, K. SCIPAL, H. BONEKAMP, J. FIGA, C. ANDERSON, 2007: Initial soil moisture retrievals from the METOP-A Advanced Scatterometer (ASCAT). - Geophys. Res. Lett. 34, L20401.

Barthlott, C., C. Hauck, G. SchÄDler, N. Kalthoff, C. KOTTMEIER, 2011: Soil moisture impacts on convective indices and precipitation over complex terrain. - Meteorol. Z. 20, 185-197.

BARTSCH, A., H. BALZTER, C. GEORGE, 2009a: The influence of regional surface soil moisture anomalies on forest fires in Siberia observed from satellites. - Environ. Res. Lett.

Bartsch, A., W., Wagner, C. Pathe, K. Scipal, D. SABel, P. WOLSKI, 2009b: Global monitoring of wetlands - the value of ENVISAT ASAR global mode. - J. Environ. Manag. 90, 2226-2233.

BIRKMANN, J., 2007: Risk and vulnerability indicators at different scales: Applicability, usefulness and policy implications. - Environ. Hazards. 7, 20-31.

Brocca, L., F. MElone, T. Moramarco, R. MORBIDElli, 2009: Antecedent wetness conditions based on ERS scatterometer data. - J. Hydrol. 364, 73-87.

Brocca, L., F. Melone, T. Moramarco, W. Wagner, S. HASENAUER, 2010a: ASCAT Soil Wetness Index validation through in-situ and modeled soil moisture data in Central Italy. - Remote Sens. Environ. 114, 2745-2755.

Brocca, L., F. Melone, T. Moramarco, W. Wagner, V. NAEIMI, Z. BARTALIS, S. HASENAUER, 2010b: Improving runoff prediction through the assimilation of the ASCAT soil moisture product. - Hydrol. Earth Sys. Sci. 14, 18811893.

Brocca, L., S. Hasenauer, T. Lacava, F. Melone, T. Moramarco, W. Wagner, W. Dorigo, P. Matgen, J. 
MARTíneZ-FernándeZ, P. Llorens, J. LATron, C. MARTIN, M. BITTELLI, 2011: Soil moisture estimation through ASCAT and AMSR-E sensors: An intercomparison and validation study accross Europe. - Remote Sens. Environ. 115, 3390-3408.

Brocca, L., T. Moramarco, F. Melone, W. Wagner, S. HASENAUER, S. HAHN, 2012a: Assimilation of Surfaceand Root-Zone ASCAT Soil Moisture Products Into Rainfall-Runoff Modeling. - IEEE Transactions on Geoscience and Remote Sensing. 50, 2542-2555.

Brocca, L., T. Tullo, F. Melone, T. Moramarco, R. MORBIDELLI, 2012b: Catchment scale soil moisture spatial-temporal variability. - J. Hydrol. 422-423, 63-75.

Brown, S. C. M., S. Quegan, K. Morrison, J. C. Bennett, G. CoOKmartin, 2003: High-Resolution Measurements of Scattering in Wheat Canopies - Implications for Crop Parameter Retrieval. - IEEE Transactions on Geoscience and Remote Sensing. 41, 1602-1610.

Ceballos, A., K. Scipal, W. Wagner, J. MartíneZFERNÁNDEZ, 2005: Validation of ERS scatterometerderived soil moisture data in the central part of the Duero Basin, Spain. - Hydrol. Processes. 19, 1549-1566.

Conraths, F. J., J. M. Gethmann, C. Staubach, T. C. Mettenleiter, M. BeEr, B. HoffmanN, 2009: Epidemiology of bluetongue virus serotype 8, Germany. Emerging Infectious Diseases. 15, 433-435.

Cosh, M. H., T. J. JACKsOn, R. Bindlish, J. H. PRUEGER, 2004: Watershed scale temporal and spatial stability of soil moisture and its role in validating satellite estimates. Remote Sens. Environ. 92, 427-435.

Crow, W. T., D. G. Miralles, M. H. Cosh, 2010a: A Quasi-Global Evaluation System for Satellite-Based Surface Soil Moisture Retrievals. - IEEE Transactions on Geoscience and Remote Sensing. 48, 2516-2527.

CROW, W. T., W. WAGNER, V. NAEIMI, 2010b: The impact of radar incidence angle on soil moisture retrieval skill. IEEE Geoscience and Remote Sensing Letters. 7, 501-505.

Crow, W. T., A. A. Berg, M. H. Cosh, A. Loew, B. P. Mohanty, R. Panciera, P. De Rosnay, D. RyU, J. P. WALKER, 2012: Upscaling sparse ground-based soil moisture observations for the validation of coarse-resolution satellite soil moisture products. - Rev. Geophys. 50, pages??

DAS, N. N., D. ENTEKHABI, E. G. NJOKU, 2011: An algorithm for merging SMAP radiometer and radar data for high-resolution soil-moisture retrieval. - IEEE Transactions on Geoscience and Remote Sensing. 49, 1504-1512.

De Jeu, R., W. Wagner, T. Holmes, H. Dolman, N. C. VAN DE GIESEN, J. FRIESEN, 2008: Global soil moisture patterns observed by space borne microwave radiometers and scatterometers. - Surveys in Geophys 29, 399-420.

De Lange, R., R. Beck, N. Van De Giesen, J. Friesen, A. DE WIT, W. WAGNER, 2008: Scatterometer-derived soil moisture calibrated for soil texture with a one-dimensional water-flow model. - IEEE Transactions on Geoscience and Remote Sensing. 46, 4041-4049.

De Rosnay, P., G. Balsamo, C. Albergel, J. MuñozSABATER, L. ISAKSE, in press a: Initialisation of land surface variables for Numerical Weather Prediction. Surveys in Geophys.

De Rosnay, P., M. Drusch, D. Vasiljevic, G. Balsamo, C. Albergel, L. ISAKSEN, In press b: A simplified Extended Kalman Filter for the global operational soil moisture analysis at ECMWF. - Quart. J. Roy. Meteor. Soc.

DE WIT, A., C. VAN DIEPEN, 2007: Crop model data assimilation with the Ensemble Kalman filter for improving regional crop yield forecasts. - Agricult. Forest Meteor. 146, 38-56.

Delwart S., C. BouzinaC, P. Wursteisen, M. Berger, M. DRINKWATER, M. MARTIN-NEIRA, Y. H. KERR, 2008: SMOS validation and the COSMOS campaigns. - IEEE Transaction on Geoscience and Remote Sensing 46, 695704.

DelWorth, T. L., S. MANABE, 1988: The Influence of Potential Evaporation on the Variabilities of Simulated Soil Wetness and Climate. - J. Climate. 1, 523-547.

Dente, L., Z. VeKerdy, J. Wen, Z. Su, 2012: Maqu network for validation of satellite-derived soil moisture products. - Int. J. Appl. Earth Obs. Geoinf. 17, 55-65.

DHARSSI, I., K. J. BOVIS, B. MACPHERSON, C. P. JONES, 2011: Operational assimilation of ASCAT surface soil wetness at the Met Office. - Hydrol. Earth Sys. Sci. 15, 2729-2746.

Dirmeyer, P. A., Z. C. GuO, X. GAO, 2004: Comparison, validation, and transferability of eight multiyear global soil wetness products. - J. Hydrometeorol. 5, 1011-1033.

DORIGO, W. A., K. ScIPAL, R. M. PARINUSSA, Y. Y. LIU, W. WAGNer, W. R. A. M. DE JeU, V. NAEIMI, 2010: Error characterisation of global active and passive microwave soil moisture datasets. - Hydrol. Earth Sys. Sci. 14, 26052616.

Dorigo, W. A., W. Wagner, R. Hohensinn, S. Hahn, S. Paulik, A. Xaver, A. Gruber, M. Drusch, S. MecklENBURG, P. VAN OEVELEN, A. ROBOCK, A. T. JACKSON, 2011: The International Soil Moisture Network: a data hosting facility for global in situ soil moisture measurements. - Hydrol. Earth Sys. Sci. 15, 1675-1698.

Draper, C., J. F. Mahfouf, J. C. CAlvet, E. Martin, W. WAGNER, 2011: Assimilation of ASCAT near-surface soil moisture into the SIM hydrological model over France. Hydrol. Earth Sys. Sci. 15, 3829-3841.

Draper, C. S., R. H. Reichle, G. J. M. De LANnoy, Q. LIU, 2012: Assimilation of passive and active microwave soil moisture retrievals. - Geophys. Res. Lett. 39, L04401.

Drusch, M., E. WoOD, H. GAO, 2005: Observation operators for the direct assimilation of TRMM microwave imager retrieved soil moisture. - Geophys. Res. Lett. 32, L15403.

EEA, 2010: Mapping the impacts of natural hazards and technological accidents in Europe. - European Environment Agency, Copenhagen, Denmark.

Eitzinger, J., H. Formayer, S. Thaler, M. TRnKA, Z. ZDENEK, V. AlEXANDROV, 2008: Aspects on results and uncertainties of climate change impact simulation studies 
for agricultural crop production in Europe. - Bodenkultur. 59, 131-147.

Elsherbini, A., K. SARABAndi, 2010: Mapping of Sand Layer Thickness in Deserts Using SAR Interferometry. Geosci. Remote Sens. IEEE Transactions on. 48, 35503559.

ENTEKhabi, D., E. G. NJOKU, P. E. O’NeiLl, K. H. Kellog, W. T. Crow, W. N. Edelstein, J. K. Entin, S. D. GoOdman, T. J. Jackson, J. Johnson, J. Kimball, J. R. Piepmeier, R. Koster, N. MArtin, K. C. MCDOnAld, M. Moghaddam, S. Moran, R. Reichle, J. C. Shi, M. W. SPEncer, S. W. Thurman, L. TSAng, J. VAN ZYL, 2010a: The Soil Moisture Active Passive (SMAP) mission. - Proceedings of the IEEE. 98, 704-716.

Entekhabi, D., R. H. Reichle, R. D. Koster, W. T. Crow, 2010b: Performance metrices for soil moisture retrievals and application requirements. - J. Hydrometeorol. 11, 832-840.

Entin, J. K., A. Robock, K. Y. Vinnikov, S. E. HollinGER, S. LIU, A. NAMKHAI, 2000: Temporal and spatial scales of observed soil moisture variations in the extratropics. - J. Geophys. Res. 105, 11865-11877.

FERRANTI, L., P. VITERBO, 2006: The European summer of 2003: Sensitivity to soil water initial conditions. - J. Climate. 19, 3659-3680.

Figa-Saldaña, J., J. J. W. Wilson, E. ATtema, R. GElSTHORPE, M. R. DRINKWATER, M. R. A. STOFFELEN, 2002: The advanced scatterometer (ASCAT) on the meteorological operational (MetOp) platform: A follow on for European wind scatterometers. - Canadian J. Remote Sens. 28, 404-412.

Fleiss, M., S. Kienberger, C. Aubrecht, R. KidD, P. ZEIL, 2011: Mapping the 2010 Pakistan floods and its impact on human life: A post-disaster assessment of socioeconomic indicators. - In: Gi4DM 2011, GeoInformation for Disaster Management., Antalya, Turkey 6.

FuNG, A. K., 1994: Microwave scattering and emission models and their applications. - Artech House, Boston.

Garcia-SaEnZ, A., P. MCCARTER, M. BAYlis, 2011: The influence of host number on the attraction of biting midges, Culicoides spp., to light traps. - Medical Veterinary Entomol 25, 113-115.

GeORgaKaKos, K. P., O. W. BAUMER, 1996: Measurement and utilization of on-site soil moisture data. - J. Hydrol. 184, 131-152.

Gouveia, C., R. M. Trigo, C. C. DA CAMARA, 2009: Drought and vegetation stress monitoring in Portugal using satellite data. - Natural Hazards Earth Sys. Sci. 9, 185195.

GrAYSON, R., G. BLÖSCHL, 2000: Spatial Processes, Organisation and Patterns. - In: R. GRAYSON, G. BLÖSCHL (Eds): Spatial Patterns in Catchment Hydrology Cambridge University Press, New York.

Gruhier, C., P. De Rosnay, S. Hasenauer, T. Holmes, R. DE Jeu, Y. Kerr, E. Mougin, E. NJOKu, F. Timouk, W. WAGNER, M. ZRIBI, 2010: Soil moisture active and passive microwave products: intercomparison and evaluation over a Sahelian site. - Hydrol. Earth Sys. Sci. 14, 141-156.
Guis, H., C. Caminade, C. Calvete, A. P. Morse, A. TRAN, M. BAYLIS, 2012: Modelling the effects of past and future climate on the risk of bluetongue emergence in Europe. - J. Roy. Soc. Interface. 9, 339-350.

HAHN, S., T. MELZER, W. WAGNER, 2012: Error Assessment of the Initial Near Real-Time METOP ASCAT Surface Soil Moisture Product. - IEEE Transactions on Geoscience and Remote Sensing. 50, 2556-2565.

Haiden, T., A. Kann, C. Wittmann, G. Pistotnik, B. BICA, C. GRUBER, 2011: The integrated nowcasting through comprehensive analysis (INCA) system and its validation over the Eastern Alpine region. - Wea. Forecast. 26, 166-183.

Hain, C. R., W. T. Crow, J. R. Mecikalski, M. C. ANDERSON, T. HOLMES, 2011: An intercomparison of available soil moisture estimates from thermal infrared and passive microwave remote sensing and land surface modeling. - J. Geophys. Res. D: Atmos. 116, D15107.

Hallikainen, M., F. T. Ulaby, M. C. Dobson, M. ElRAYES, 1984: Dielectric measurements of soils in the 3- to $37-\mathrm{GHz}$ band between $-50{ }^{\circ} \mathrm{C}$ and $23{ }^{\circ} \mathrm{C}$. - In: IGARSS '84. Strasbourg. 1, 163-168.

Hartemink, N. A., B. V. Purse, R. Meiswinkel, H. E. Brown, A. DE KoeiJer, A. R. W. Elbers, G. J. Boender, D. J. Rogers, J. A. P. HeEsterbeeK, 2009: Mapping the basic reproduction number ( $\mathrm{R} 0$ ) for vectorborne diseases: A case study on bluetongue virus. Epidemics. 1, 153-161.

HILLEL, D., 1982: Introduction to Soil Physics. - Academic Press, San Diego, 364pp.

Hoffmann, B., M. Scheuch, D. HÖPER, R. JungBlut, M. Holsteg, H. SChirRmeier, M. Eschbaumer, K. V. Goller, K. Wernike, M. Fischer, A. Breithaupt, T. C. METTENLEITER, M. BEER, 2012: Novel orthobunyavirus in cattle, Europe, 2011: - Emerging Infectious Diseases. 18, 469-472.

Hoogenboom, G., J. C. Jones, P. Porter, K. Wilkens, W. BoOTE, L. BATCHELOR, G. HuNT, G. TSUJ, 2004: DSSAT 4.0. vol. 1. Overview. - ICASA.

HOOGENDAM, K., 2007: International study on the economic consequences of outbreaks of Bluetongue serotype 8 in north-western Europe. - Van Hall Institute, Leeuwarden.

HSIEH, C.-Y., A. K. FunG, G. NeSti, A. J. SieBER, P. COPPO, 1997: A further study of the IEM surface scattering model. - IEEE Transaction on Geoscience and Remote Sensing 35, 901-909.

IPCC, 2012: Managing the Risks of Extreme Events and Disasters to Advance Climate Change Adaptation. - A Special Report of Working Groups I and II of the Intergovernmental Panel on Climate Change Intergovernmental Panel on Climate Change, Cambridge, UK, and New York, NY, USA.

ISAKSEN, L., A. STOFFELEN, 2000: ERS scatterometer wind data impact on ECMWF's tropical cyclone forecasts. IEEE Transactions on Geoscience and Remote Sensing. 38, 1885-1892.

JACKSON, T. J., M. H. COSH, R. BINDLish, P. J. StARKS, D. D. Bosch, M. SEYFried, D. D. GOODRICH, M. S. 
MORAN, J. Y. DU, 2010: Validation of Advanced Microwave Scanning Radiometer Soil Moisture Products. IEEE Transactions on Geoscience and Remote Sensing. 48, 4256-4272.

Jerez, S., J. P. Montavez, J. J. Gomez-Navarro, P. JiMENEZ-GUERRERO, J. M. JIMENEZ, J. F. GONZALEZRouCO, 2010: Temperature sensitivity to the land-surface model in MM5 climate simulations over the Iberian Peninsula. - Meteorol. Z. 19, 363-374.

JUNGBLUT, C., S. SCHOBER, 2011: Risk assessment methods for bluetongue diesease (in German), Veterinärmedizinische Universität Wien, Vienna.

Jupp, T. E., C. M. TAYlor, H. BAlzTER, C. T. GeOrge, 2006: A statistical model linking Siberian forest fire scars with early summer rainfall anomalies. - Geophys. Res. Lett. 33, L14701

KAsischKe, E. S., L. L. Bourgeau-ChaVez, J. F. JOHNSTONE, 2007: Assessing spatial and temporal variations in surface soil moisture in fire-disturbed black spruce forests in Interior Alaska using spaceborne synthetic aperture radar imagery - Implications for post-fire tree recruitment. - Rem. Sens. Environ. 108, 42-58.

KERR, Y. H., 2007: Soil moisture from space: Where are we? - Hydrogeol. J. 15, 117-120.

Kerr, Y., P. WALdTeufel, J.-P. Wigneron, S. DelWart, F. CABOt, J. Boutin, M.-J. Escorihuela, J. Font, N. Reul, C. Gruhier, S. E. Juglea, M. R. Drinkwater, A. HAHNE, M. MARTIN-NEIRA, M. MECKLENBURG, 2010: The SMOS mission: New tool for monitoring key elements of the global water cycle. - Proceedings of the IEEE. 98, 666-687.

KIDD R. A., 2005: Discrete Global Grid Systems, Institute of Photogrammetry and Remote Sensing. - Vienna University of Technology, Austria.

Koster, R. D., P. A. Dirmeyer, Z. C. Guo, G. Bonan, E. Chan, P. Cox, C. T. Gordon, S. Kanae, E. KowALCZYK, D. LAWRENCE, P. LIU, C. H. LU, S. MALYShEV, B. Mcavaney, K. Mitchell, D. Mocko, T. OKi, K. Oleson, A. Pitman, Y. C. Sud, C. M. Taylor, D. Verseghy, R. VAsic, Y. K. Xue, T. YAMAdA, G. TEAM, 2004: Regions of strong coupling between soil moisture and precipitation. - Science. 305, 1138-1140.

Koster, R. D., Z. Guo, R. Yang, P. A. Dirmeyer, K. Mitchell, M. J. PuMA, 2009: On the Nature of Soil Moisture in Land Surface Models. - J. Climate. 22, 43224335 .

Krauss, L., C. HaucK, C. KotTMEIER, 2010: Spatiotemporal soil moisture variability in Southwest Germany observed with a new monitoring network within the COPS domain. - Meteorol. Z. 19, 523-537.

Leblon, B., E. KAsischKe, M. AleXAnder, M. Doyle, M. ABBOTT, 2002: Fire danger monitoring using ERS-1 SAR images in the case of northern boreal forests. - Natural Hazards. 27, 231-255.

Legates, D. R., R. Mahmood, D. F. Levia, T. L. Deliberty, S. M. Quiring, C. Houser, F. E. Nelson, 2011: Soil moisture: A central and unifying theme in physical geography. - Prog. Phys. Geography. 35, 65-86.
LEHNER, B., P. DÖLL, 2004: Development and validation of a global database of lakes, reservoirs and wetlands. - J. Hydrol. 296, 1-22.

LerouX D. J., Y. H. KeRR, P. Richaume, B. Berthelot, 2011: Estimating SMOS error structure using triple collocation. - In: IGARSS'20122 Vancouver, 24-27.

Lin, C. C., M. BetTo, M. BelmonteRivas, A. Stoffelen, J. DE KLOE, 2012: EPS-SG windscatterometer concept tradeoffs and wind retrieval performance assessment. IEEE Transactions on Geoscience and Remote Sensing. 50, 2458-2472.

LIU, W. T., 2002: Progress in Scatterometer Application. - J. Oceanography. 58, 121-136.

LiU, Y. Y., R. M. Parinussa, W. A. Dorigo, R. A. M. DE Jeu, W. Wagner, A. Van DiJK, F. M. MCCABe, J. P. EVANS, 2011: Developing an improved soil moisture dataset by blending passive and active microwave satellite-based retrievals. - Hydrol. Earth Sys. Sci. 15, 425-436.

MAGAGI, R. D., Y. H. KERR, 1997: Retrieval of soil moisture and vegetation characteristics by use of ERS-1 wind scatterometer over arid and semi-arid areas. - J. Hydrol. 188-189, 361-384.

MAHFOUF, J.-F., 2010: Assimilation of satellite-derived soil moisture from ASCAT in a limited-area NWP model. Quat. J. Roy. Meteor. Soc. 136, 784-798.

Matgen, P., F. Fenicia, S. Heitz, D. Plaza, R. DE Keyser, V. R. N. PauWels, W. Wagner, H. SAVEniJe, 2012a: Can ASCAT-derived soil wetness indices reduce predictive uncertainty in well-gauged areas? A comparison with in situ observed soil moisture in an assimilation application. - Advan. Water Resourc. 44, 49-65.

Matgen, P., S. Heitz, S. Hasenauer, C. Hissler, L. Brocca, L. HofFMAnN, M. WAGNer, H. H. G. SAVEniJe, 2012b: On the potential of MetOp ASCAT-derived soil wetness indices as a new aperture for hydrological monitoring and prediction: a field evaluation over Luxembourg. - Hydrol. Processes. 26, 2346-2359.

MÄTZLER, C., 1998: Microwave permittivity of dry sand. IEEE Transactions on Geoscience and Remote Sensing. 36 (1), 317-319.

MEIER, P., A. W. Kinzelbach. FRÖMELT, 2011: Hydrological real-time modelling in the Zambezi river basin using satellite-based soil moisture and rainfall data. - Hydrol. Earth Sys. Sci. 15, 999-1008.

Miralles, D. G., W. T. Crow, M. H. Cosh, 2010: Estimating spatial sampling errors in coarse-scale soil moisture estimates derived from point-scale observations. - J. Hydrometeorol. 11, 1423-1429.

Montosi, E., S. MAnZONI, A. Porporato, A. MontanARI, 2012: An eco-hydrologic model of malaria outbreaks. Hydrol. Earth Sys. Sci. Discus. 9, 2831-2854.

NAEIMI, V., Z. BARTALIS, W. WAGNER, 2009a: ASCAT soil moisture: An assessment of the data quality and consistency with the ERS scatterometer heritage. - J. Hydrometeorol. 10, 555-563.

NAEIMi V., K. Scipal, Z. Bartalis, S. Hasenauer, W. WAGNER, 2009b: An improved soil moisture retrieval 
algorithm for ERS and METOP scatterometer observations. - IEEE Transaction on Geoscience and Remote Sensing 47, 1999-2013.

Nolin, A., R. L. Armstrong, J. Maslanik, 1998: NearReal-Time SSM/I-SSMIS EASE-Grid Daily Global Ice Concentration and Snow Extent. - In: C.U.N.S.a.I.D.C.D.m. Boulder (Editor).

OWE, M., R. DE JEU, T. HOLMES, 2008: Multisensor historical climatology of satellite-derived global land surface moisture. - J. Geophys. Res.-Earth Surface 113, F01002.

PARAJKA, J., V. NAEIMI, G. BLÖSCHL, J. KOMMA, 2009: Matching ERS scatterometer bades soil moisture patterns with simulations of a conceptual dual layer hydrologic model over Austria. - Hydrol. Earth Syst. Sci. 13, 259-271.

Parrens, M., E. Zakharova, S. LAfont, J.-C. CAlvet, W. KerR, W. WAGNer, J.-P. Wigneron, 2012: Comparing soil moisture retrievals from SMOS and ASCAT over France. - Hydrol. Earth Sys. Sci. 16, 423-440.

Pellarin, T., J.-C. CAlvet, W. WAgner, 2006: Evaluation of ERS scatterometer soil moisture products over a halfdegree region in southwestern France. - Geophys. Res. Lett. 33, L17401.

Piles, M., A. Camps, M. Vall-Llossera, I. Corbella, R. PANCIERA, C. Rudiger, Y. H. KERR, J. WALKER, 2011: Downscaling SMOS-derived soil moisture using MODIS visible/infrared data. - IEEE Transactions on Geoscience and Remote Sensing. 49, 3156-3166.

Pulliainen, J. T., P. J. MikKElä, M. T. Hallikainen, J.-P. IKONEN, 1996: Seasonal Dynamics of C-Band Backscatter of Boreal Forests with Applications to Biomass and Soil Moisture Estimation. - IEEE Transactions on Geoscience and Remote Sensing. 34, 758-770.

Pulliainen, J. T., T. Manninen, M. T. Hallikainen, 1998: Application of ERS-1 wind scatterometer data to soil frost and soil moisture monitoring in boreal forest zone. IEEE Transactions on Geoscience and Remote Sensing. 36, 849-863.

Reichle, R. H., R. D. Koster, J. Dong, A. A. Berg, 2004: Global Soil Moisture from Satellite Observation, Land Surface Models, and Ground Data: Implications for Data Assimilation. - Journal of Hydrometeorology. 5, 430-442.

Reichle, R. H., R. D. Koster, P. LiU, S. P. P. Mahanama, E. G. NJOKU, M. OWE, 2007: Comparison and assimilation of global soil moisture retrievals from the Advanced Microwave Scanning Radiometer for the Earth Observing System (AMSR-E) and the Scanning Multichannel Microwave Radiometer (SMMR). - J. Geophys. Res. Atmos. 112, D09-108.

RosemA, A., 1993: Using METEOSAT for operational evapotranspiration and biomass monitoring in the Sahel region. - Remote Sens. Environ. 46, 27-44.

RÜDIGER, C., G. HANCOCK, H. M. HEMAKUMARA, B. Jacobs, J. D. Kalma, C. Martinez, M. Thyer, J. P. WALKeR, T. Wells, G. R. WillgOOSE, 2007: Goulburn River experimental catchment data set. - Water Resour. Res. 43, W10403.

RÜDiger, C., T. Holmes, J.-C. CAlvet, R. DE JeU, W. WAGNER, 2009: An intercomparision of ERS-Scat and
AMSR-E soil moisture observations with Model Simulations over France. - J. Hydrometeorol. 10, 431-447.

SCHANDA, E., 1986: Physical fundamentals of remote sensing. - Springer Verlag, Berlin Heidelberg, New York Tokyo, 187.

SchÄR, C., D. Luethi, U. Beyerle, E. Heise, 1999: The soil - precipitation feedback: A process study with a regional climate model. - J. Climate. 12, 722-741.

Schumann, G., P. D. Bates, M. S. Horritt, P. Matgen, F. PAPPENBERGER, 2009: Progress in integration of remote sensing-derived flood extent and stage data and hydraulic models. - Rev. Geophys. 47, 2008RG000274.

SCIPAL, K., W. WAGNER, M. TROMMLER, K. NAUMANN, 2002: The Global Soil Moisture Archive 1992-2000 from ERS Scatterometer Data: First Results. -Proceedings of the IGARSS 2002.

SCIPAL, K., C. Scheffler, W. WAGNER, 2005: Soil moisture-runoff relation at the catchment scale as observed with coarse resolution microwave remote sensing. Hydrol. Earth Sys. Sci. 9, 173-183.

ScIPAL, K., M. Drusch, M. WAGNER, W., 2008a: Assimilation of a ERS scatterometer derived soil moisture index in the ECMWF numerical weather prediction system. Advan. Water Resour. 31, 1101-1112.

ScIPAL, K., T. Holmes, R. DE JEU, V. NAEIMI, W. WAGNER, 2008b: A possible solution for the problem of estimating the error structure of global soil moisture data sets. Geophys. Res. Lett. 35, L24403: 1-4.

SEUfFERT, G., P. Gross, C. SiMMER, E. F. WoOD, 2002: The influence of hydrologic modelling on the predicted local weather: Two-way coupling of a mesoscale weather prediction model and a land surface hydrologic model. J. Hydrometeorol. 3, 505-523.

Sinclair, S., G. G. S. Pegram, 2010: A comparison of ASCAT and modelled soil moisture over South Africa, using TOPKAPI in land surface mode. - Hydrol. Earth Sys. Sci. 14, 613-626.

STOFFELEN, A., 1998: Toward the true near-surface wind speed: Error modeling and calibration using triple collocation.. - J. Geophys. Res. C: Oceans. 103, 7755-7766.

TAYlor, C. M., R. A. M. DE JeU, F. Guichard, P. P. HARRIS, W. A. DORIGO, 2012: Afternoon rain more likely over drier soils. - Nature 489, 423-426.

Teng, W. L., J. R. WAnG, P. C. Doraiswamy, 1993: Relationship between satellite microwave radiometric data, antecedent precipitation index, and regional soil-moisture. - Int. J. Remote Sens. 14, 2483-2500.

Ulaby, F. T., B. MoOre, A. K. Fung, 1982: Microwave Remote Sensing - Active and Passive, Vol. II: Radar Remote Sensing and Surface Scattering and Emission Theory. - Artech House, Norwood.

Ulaby, F. T., R. K. Moore, A. K. Fung, 1986: Microwave Remote Sensing: Active and Passive. Vol. III. - Volume Scattering and Emission Theory, Advanced Systems and Applications Artech House, Inc, Dedham, MA, USA.

Uppala, S. M., P. W. KallberG, A. J. Simmons, COAUTHORS, 2005: The ERA-40 re-analysis. - Quart. J. Roy. Meteor. Soc. 131, 2961-3012. 
Vachaud, G., A. Passerat De Silans, P. Balabanis, M. VAUCLIN, 1985: Temporal Stability of Spatially Measured Soil Water Probability Density Function. - Soil Sci. Soc. America J. 49, 822-828.

Verhoest N. E., H. Lievens, W. WAgner, J. AlvarezMozos, M. S. Moran, F. MATTIA, 2008: On the soil roughness parameterization problem in soil moisture retrieval of bare surfaces from Synthetic Aperture Radar. - Sensors 8, 4213-4248.

Verstraeten, W. W., F. Veroustraete, W. Wagner, T. VAN RoEy, W. HEyns, S. VERBEIREN, J. FEYEN, 2010: Remotely sensed soil moisture integration in an ecosystem carbon flux model. The spatial implication. - Climatic Change. 103, 117-136.

Vinnikov, K. Y., A. Robock, N. A. Speranskaya, A. SCHLOSSER, 1996: Scales of temporal and spatial variability of midlatitude soil moisture. - J. Geophys. Res. Atmos. 101, 7163-7174.

VINNIKOV, K. Y., A. Robock, S. QIU, J. K. EnTIN, M. OWE, B. J. Choudhury, S. E. Hollinger, E. G. NJOKU, 1999: Satellite remote sensing of soil moisture in Illinois, United States. - J. Geophys. Res. D: Atmospheres. 104, 4145-4168.

Vischel, T., G. G. S. PEGRAM, S. SinClair, W. WAGNER, A. BARTSCH, 2008: Comparison of soil moisture fields estimated by catchment modelling and remote sensing: a case study in South Africa. - Hydrol. Earth Sys. Sci. 12, 751-767.

WAGNER, W., 1998: Vegetation as observed with the AVHRR and the ERS Scatterometer: A case study over the Iberian Peninsula. - In: Joint ESA-EUMETSAT Workshop on Emerging Scatterometer Applications From Research to Operations, Noordwijk, The Netherlands. 424, 51-56.

Wagner, W., G. LEMOINE, M. Borgeaud, H. RotT, 1999a: A Study of Vegetation Cover Effects on ERS Scatterometer Data. - IEEE Transactions on Geoscience and Remote Sensing. 37, 938-948.

Wagner, W., G. Lemoine, H. RotT, 1999b: A Method for Estimating Soil Moisture from ERS Scatterometer and Soil Data. - Remote Sens. Environ. 70, 191-207.

Wagner, W., J. Noll, M. Borgeaud, H. RotT, 1999c: Monitoring soil Moisture over the Canadian Prairies with the ERS Scatterometer. - IEEE Trans. Geosci. Rem. Sens. 37, 206-216.

Wagner, W., K. Scipal, C. Pathe, D. Gerten, W. Lucht, B. RUDOLF, 2003: Evaluation of the agreement between the first global remotely sensed soil moisture data with model and precipitation data. - J. Geophys. Res. D: Atmospheres. 108, 4611-4642.

Wagner W., G. Blöschl, P. PAMPaloni, J.-C. CAlvet, B. BIZZARRI, J.-P. WIGNERON, Y. KERR, 2007a: Operational readiness of microwave remote sensing of soil moisture for hydrologic applications. - Nordic Hydrol. 38, 1-20.

WAgner, W., V. NAEIMI, K. Scipal, R. DE JeU, J. MARTINEZ-FERNANDEZ, 2007b: Soil moisture from operational meteorological satellites. - Hydrogeol. J. 15, 121131 .
Wagner W., C. Pathe, M. Doubkova, D. Sabel, A. Bartsch, S. HASENAUER, G. BlÖSChl, K. ScIPAL, J. MARTINEZ-FERNANDEZ, A. LÖW, 2008: Temporal stability of soil moisture and radar backscatter observed by the Advanced Synthetic Aperture Radar (ASAR). - Sensors 8, 1174-1197.

WAgner, W., Z. BARTAlis, V. NAEIMI, S.-E. PARK, J. FigASALDANA, H. BONEKAMP, 2010: Status of the METOP ASCAT soil moisture product. - In: IEEE Geoscience and Remote Sensing Symposium (IGARSS'2010) Honolulu, USA, 276-279.

WANG, Y., T. HAIDEN, A. KANN, 2006: The operational limited-area modelling system at ZAMG: ALADIN-Austria. - Österreichische Beiträge $\mathrm{zu}$ Meteorologie und Geophysik 3, ISSN:1016-6254.

WANG, Y., M. Bellus, C. WitTMANN, M. SteinhEIMER, F. WEIDLE, A. KANN, S. IVATEK-ŠAHDAN, W. TIAN, X. MA, S. TASCU, E. BAZILE, 2011: The Central European limitedarea ensemble forecasting system: ALADIN-LAEF. Quart. J. Roy. Meteor. Soc. 137, 483-502.

WEN, J., Z. B. SU, 2003: A time series based method for estimating relative soil moisture with ERS wind scatterometer data. - Geophys. Res. Lett. 30, 1397.

Wernli, H., M. Paulat, M. Hagen, C. Frei, 2008: SAL A novel quality measure for the verification of quantitative precipitation forecasts. - Mon. Wea. Rev. 136, 4470-4487.

Western, A. W., R. GRAYSON, G. BlÖSCHL, 2002: Scaling of soil moisture: a hydrologic perspective. - Ann. Rev. Earth Planetary Sci. 30, 149-180.

Williams, K. K., R. GREELEY, 2001: Radar attenuation by sand: laboratory measurements of radar transmission. IEEE Transactions on Geoscience and Remote Sensing. 39, 2521-2526.

Wilson, J. J. W., C. Anderson, M. A. BAKER, H. BONEKAMP, J. Fig. SAldAÑA, R. G. DYer, LERCH, G. KAYAl, R. V. Gelsthorpe, M. A. BROWN, E. SChIED, S. Schutz-Munz, F. Rostan, E. W. Pritchard, N. G. WRIGHT, D. KING, Ü. ÖNEL, 2010: Radiometric calibration of the Advanced Wind Scatterometer Radar ASCAT carried on-board the METOP-A satellite. - IEEE Transaction on Geoscience and Remote Sensing 48, 3236-3255.

Woodhouse, I. H., D. H. HoEkMan, 2000: Determining land-surface parameters from the ERS wind scatterometer. - IEEE Transactions on Geoscience and Remote Sensing. 38, 126-140.

XiAO, J., Q. ZHUANG, 2007: Drought effects on large fire activity in Canadian and Alaskan forests. - Environ. Res. Lett. 2, Pages??.

ZHAO, D., B. SU, M. ZHAO, 2006: Soil moisture retrieval from satellite images and its application to heavy rainfall simulation in eastern China. - Advan. Atmos. Sci. 23, 299-316.

ZHENG, X. Y., E. A. B. ELTAHIR, 1998: A soil moisture rainfall feedback mechanism 2. Numerical experiments. Water Resour. Res. 34, 777-785.

ZRIBI, M., C. ANDRÉ, B. DECHARMe, 2008: A method for soil moisture estimation in Western Africa based on the 
ERS scatterometer. - IEEE Transactions on Geoscience and Remote Sensing. 46, 438-448.

Zribi, M., T. Paris-Anguela, B. Duchemin, Z. Lili, W. Wagner, S. Hasenauer, A. Chehbouni, 2010: Relationship between soil moisture and vegetation in the Kairouan plain region of Tunisia using low spatial resolution satellite data. - Water Resour. Res. 46, W06508.
Zwieback, S., K. Scipal, W. Dorigo, W. WAGNer, 2012 Structural and statistical properties of the collocation technique for error characterization. - Nonlinear Processes in Geophys 19, 69-80. 